Portland State University

PDXScholar

\title{
A study of the correlation between the degree of acculturation and scholastic achievement and English gain of ESL students, grades 2-5, Beach School, Portland, Oregon
}

Rhona R. Blackton

Portland State University

Follow this and additional works at: https://pdxscholar.library.pdx.edu/open_access_etds

Part of the Communication Commons, and the English Language and Literature Commons Let us know how access to this document benefits you.

\section{Recommended Citation}

Blackton, Rhona R., "A study of the correlation between the degree of acculturation and scholastic achievement and English gain of ESL students, grades 2-5, Beach School, Portland, Oregon" (1986). Dissertations and Theses. Paper 3560.

https://doi.org/10.15760/etd.5442

This Thesis is brought to you for free and open access. It has been accepted for inclusion in Dissertations and Theses by an authorized administrator of PDXScholar. Please contact us if we can make this document more accessible: pdxscholar@pdx.edu. 
AN ABSTRACT DF THE THESIS DF RhOMa $R$. Blackton for the Master of Arts in Speech Communication May 13, 1986.

Title: A Study of the Correlation between the Degree of Acculturation and Scholastic Achievement and English Gain of ESL Students, Grades 2 - 5, Beach School, Portland, Oregon.

APPROVED BY MEMBERS OF THE THESIS COMMITTEE:

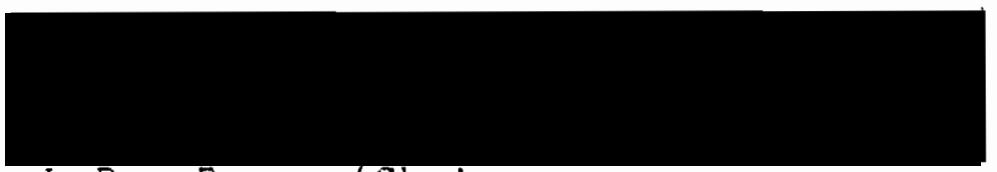

LaRay Barnaft Chairman

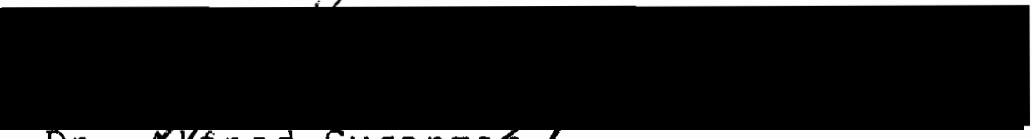

Dr. $\not X$ fred sugarmán

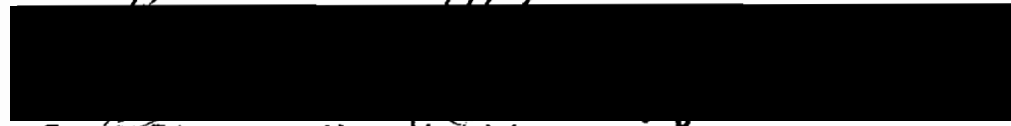

Dr. Steven Kosdköf

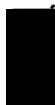

Shirley Mórrell

The purpose of this study is to determine if a correlation exists between the degree of acculturation and achievement in English, reading and math of English as a Second Language (ESL) students in grades 2 to 5 . This study is intended to provide insights about the acculturating ESL student, and suggests how educators can best meet students' needs. 
Franco's (1983) Child Acculturation Scale (CAS) was administered by the ESL teacher to 32 ESL students, grades 2 to 5 at Beach School, Portland, Oregon to determine individual levels of acculturation. Achievement growth (Fall, 1984 to Fall, 1985) in Portland Achievement Level Tests (PALT) in reading and math and gain in Individualized Developmental English Ability (IDEA) was correlated with individual degrees of acculturation using Spearman's Rho measure of rank correlation.

The findings support the hypothesis that an ESL student's degree or level of acculturation is a significant factor in his academic growth in English language competency (.999) and math (.975) and that there is a positive, though not significant correlation between degree of acculturation and reading $(.90)$. 
A STUDY OF THE CORRELATION BETWEEN THE DEGREE OF ACCULTURATION AND SCHOLASTIC ACHIEVEMENT AND ENGLISH GAIN OF ESL STUDENTS, GRADES 2 - 5, BEACH SCHOOL, PORTLAND, OREGON

by
RHONA BLACKTON

A thesis submitted in partial fulfillment of the requirements for the degree of

MASTER OF ARTS
in
SPEECH COMMUNICATION

Portland State University 1986 
TO THE OFFICE OF GRADUATE STUDIES AND RESEARCH:

The members of the Committee approve the thesis of Rhona Blackton presented May 13, 1986.
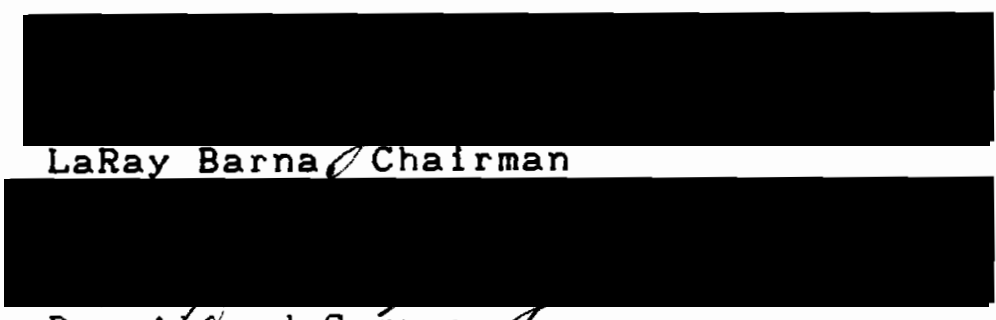

Dr. Affred Sugarmaxy
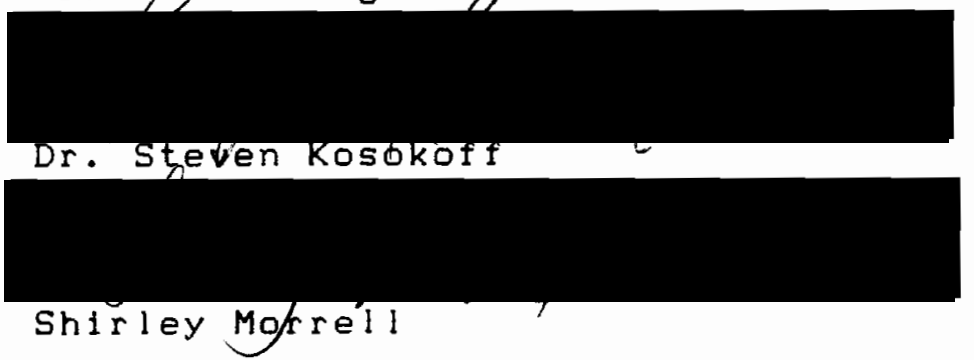

APPROVED :

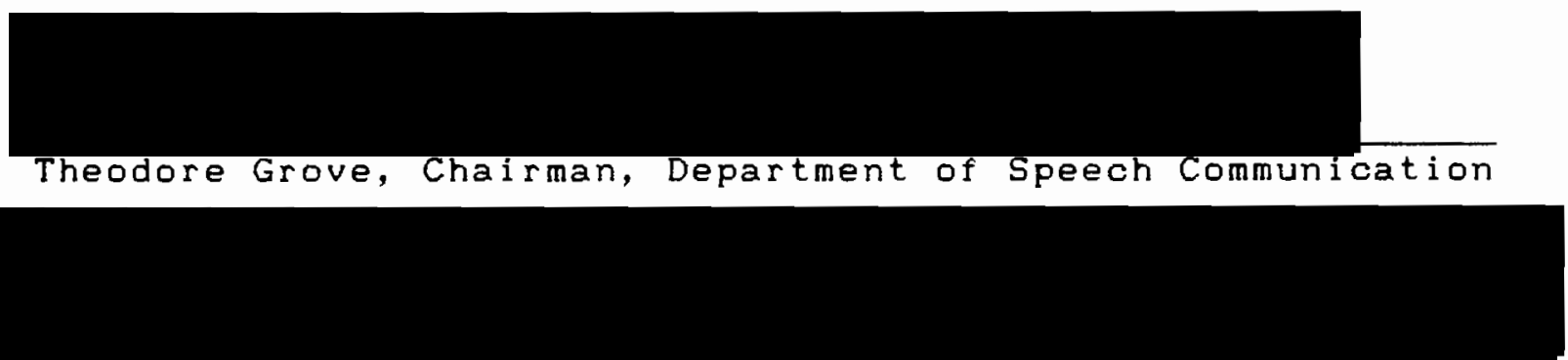

Bernard Ross, Dean of Graduate Studies and Research 
"The newcomers could not look back; their departure was decisive. They had abandoned their past and consequently had only the future toward which to look. Having left their parents, they rested their hope for stability on their children."

Oscar Handlin (1966) 


\section{ACKNOWLEDGMENTS}

I would like to express my gratitude towards family and friends who gave me their support and guidance throughout this study.

First, a word of thanks to Gary, Tim and Sara who managed to keep encouraging me, gave me the time to work and reflect and shared the responsibilities at home when my thoughts were on theory, not dinner.

My parents, Mildred and Murray Kaplan, deserve a special thank you: for giving me the gift of understanding the value of education. I especially appreciate my father's assistance in locating periodicals that no one else could f ind.

Mrs. Barna, who has served as a role model, teacher and friend, also deserves great appreciation, for without her encouragement to pursue graduate study and her guidance over the past five years, this project could not have been completed - or begun!

Also deserving gratitude are Dr. Sugarman and Dr. Kosokoff, the Committee Members who supported me with ideas and encouragement, Kathy Holland, Russ Wayland, Connie Stanton, who provided technical assistance, and the English as a Second Language Department of Portland Public Schools. 
TABLE OF CONTENTS

PAGE

ACKNOWLEDGEMENTS

CHAPTER

I INTRODUCTION AND JUSTIFICATION

I I LITERATURE REVIEW . . . . . . . . . . . 6

Culture - Definition and Purpose . . . . 6

Acculturation . . . . . . . . . . . 9

A Multi-Dimensional Process

Summary/Definition to Be Used

Acculturation and Children . . . . . . . 18

The School

Language Development

Ethnicity and Identity

The Family

Summary

Scales of Acculturation for Use with Children 35

Scales $1924-1933$

Hof fman Bilingual Scale

Olmedo's Variables

Franco's CAS

Summary 
III DESIGN OF STUDY • . . . . . . . . . . . . .

Purpose

Hypotheses . . . . . . . . . . . . . . 46

Definitions . . . . . . . . . . . . . 4 47

Measuring Instrument for Acculturation . . . 48

Criteria for Measuring Instrument

Selection of the CAS Scale

Description of the Child Acculturation Scale

Other Measuring Instruments . . . . . . .

Methodology . . . . . . . . . . . . . 54

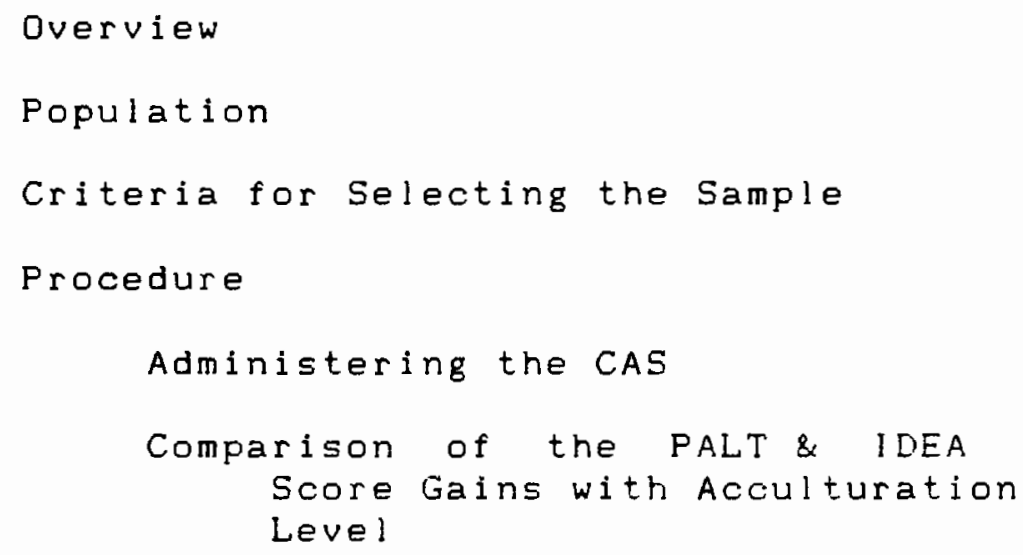

I V

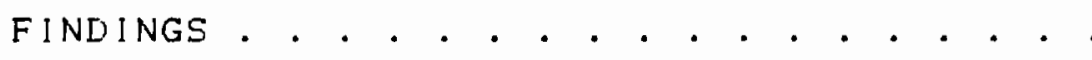

$$
\begin{aligned}
& \text { Degree of Acculturation . . . . . . . . . } \\
& \text { Comparison of PALT and Idea Gain } \\
& \text { with Acculturation Level . . . . . . } \\
& \text { Acculturation Level vs. Reading Gain } \\
& \text { Acculturation Level vs. Math Gain } \\
& \text { Acculturation Level vs. English (IDEA) } \\
& \text { Gain }
\end{aligned}
$$


V DISCUSSION . . . . . . . . . . . . . . . . 67 Interpretation of Findings . . . . . . . 67

Limitations of Study . . . . . . . . . 73

Suggestions for Further Research . . . . . 75

VI APPLICATIONS • . . . . . . . . . . . . 77

Conclusion... . . . . . . . . . . . 81

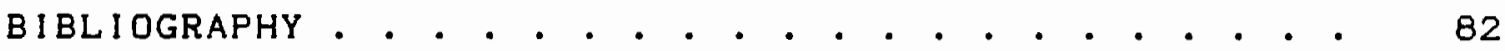

APPENDIX . . . . . . . . . . . . . . . . . . . . . . 87

A Child Acculturation Scale (Franco 1983) . . 87

B IDEA Profile... . . . . . . . . . . . 89 


\section{CHAPTER I}

\section{INTRODUCTION AND JUSTIFICATION}

In the mid-seventies, Immigration to the United States increased dramatically. At the expense of leaving their homelands, people sought a chance to maintain their native values peacefully in a new country. The cultural adjustment demanded of them was tremendous - many of the $1 \mathrm{~mm}$ igrants were farmers who had no formal education and were used to a very simple way of life. Life here was a shock, and understanding the responsibilities that are a part freedom in this country was difficult.

Families are still adapting to life here. They brought with them a rich cultural heritage that is an important part of their identity. Yet, in order to function in American society, new behaviors had to be learned. The children and young people were affected the most, as they were caught between the old and new cultures. They were a part of both.

As a result of being caught between two worlds, some Immigrant children experience problems in school, at home and problems in trying to figure out where they really do fit.

Portland Public Schools has approximately 1,000 (19841985 school year) children enrolled in the English as a Second Language (ESL) program in the elementary schools, 
grades kindergarten to five. Most are the children of immigrants who left their native lands in search of freedom. Portland Public Schools is committed to providing academic and English instruction and psychological/emotional support for these children as they adapt to life here.

The children receive ESL instruction, mainstream classroom lessons and native language tutoring by Bilingual Aldes. It is commonly believed that the majority of ESL students become literate in English within three years, depending on their age, previous education and family support.

There is, however, a group of students of similar age, education and family support, who are not progressing as well as their ESL peers. They have been tested and tutored, but no specific reason for their lack of progress has been identified. These students often have a difficult time at school. They are frustrated because they cannot cope, whether it be academically or socially, in the school environment. They see many of their peers succeeding and do not understand why they aren't succeeding as well. These students are tempted to withdraw or turn away from trying to learn or achieve in school due to their frustrations.

Most ESL teachers try to give extra help to these students by working one on one with them for academic tutoring, making sure they experience some form of success throughout the day and by helping mainstream classroom 
teachers to set individual student goals that are attainable. Unfortunately, these efforts are not always enough. Students often fall below grade level and/or have behavioral and emotional problems.

Bilingual social workers and psychologists have suggested that these students are having problems acculturating to life in Portland, especially in the school. Perhaps the pressure to maintain the ethnic lifestyle and traditions of their families and at the same time participate and learn in the public school is too great. It is thought that these students are not sure which code of behavior and values are appropriate and how to shift from one cultural reality to another.

These theories and questions of educators need investigation: Is the process of adapting to a new cultural reality while maintaining native ethnic identity creating stress and problems that negatively influence learning and achievement ability? ls there a correlation between the degree of acculturation and individual student achievement? This seems reasonable, almost obvious to those acquainted with children, but academicians have not been made aware of this possibility. This theory can be found in literature, but few empirical studies have been undertaken to support it. If a correlation between acculturation and academic achievement is proven to be statistically significant, both educators and academicians will be encouraged to work 
together to develop theory, teaching strategies and curriculum that will meet the needs of the acculturating student.

School administrators and teachers might want to direct more of their energies toward helping children cope with the process of acculturation as opposed to emphasizing the mastery of academic curriculum.

A measure of student acculturation will also make it possible to investigate other problems of interest to the educator such as a comparison of length of residency and acculturation, acculturation differences between males and females, and comparison of acculturation levels of various ethnic groups. It will be useful in surveys and comparative studies in these fields as well.

A measure of student acculturation level could also aid the mainstream and ESL teacher in initial grade placement, classroom grouping and help them to acquire a better understanding of individual and group differences among ESL students.

Lastly, understanding a student's degree of acculturation can provide insights in regard to his strengths, problems, abilities and attitudes. The more information a teacher has about his students, the better he is able to teach them. He knows what student needs exist, and he can develop strategies to effectively meet them. 
Purpose

The purpose of this study is to determine if a correlation exists between the degree of acculturation and achievement in English, reading and math of English as a Second Language (ESL) students in grade 2 to 5 , Beach School, Portland, Dregon.

A secondary purpose is to determine if a scale of acculturation for use with children has been developed. 


\section{CHAPTER II}

\section{LITERATURE REVIEW}

\section{CULTURE - DEFINITION AND PURPOSE}

Culture is the environment around us. It is the system of behavior that we accept as appropriate and includes traditional patterns of thinking and their attached values. Brislin (1981) says: "Culture refers to those aspects of a society that all the members share, are familiar with, and pass on to the next generation." ( $p .51$ ) It is learned by observation and perception, without our seeking it out. Culture plays a powerful role in our lives.

Culture provides the code of behavior and the code for interpretation of behavior. It directs us in setting goals and objectives. A number of authors have made this clear. Becker (1962) says, "Culture provides the action goals for an individual by introducing the possibility of choice between alternatives, and weighting them according to degrees of rightness and wrongness." (p.86) In other words, culture establishes a framework of acceptable behaviors within a specific cultural reality.

This framework becomes a dependable guide. By creating predictability, culture minimizes anxiety. It lays out the acceptable procedures on how to get things done. It also 
encourages interpersonal relationships. Becker also says that within a culture "the individual can count on others to behave according to his expectations." (p.85) People serve as identifiable links to each other within a cultural chain of interactions.

Hall (1977) says: "One of the functions of culture is to provide a highly selective screen between man and the outside world...culture therefore designates what we pay attention to and what we ignore." (p.85) It helps us to define our needs and tells us what we can do to meet them.

His second idea is that culture provides context. As Hall says, "...an event is usually infinitely more complex and rich than the language used to describe it." (p.87) Culture combines the senses and cognition by giving culturally based meaning to interpretation.

Hall says that intelligence is paying attention to the right things. In a different culture, the "right" things could be the wrong things. When an individual is in his native culture, he is able to use his intelligence to communicate effectively. He is able to context internally, "automatically correcting for distortions or omissions of information." (p.116) He knows what to pay attention to, what to ignore, what to correct.

In other words, culture provides a sense of appropriateness. Brislin (1981) says: "People able to perceive feedback from hosts are likely to obtain the 
necessary information so they can modify their behavior... " (p.62) He adds, however, that when the boundaries of a culture are unknown, and people are unfamiliar with the environment, they don't interact effectively because they don't know how. Often they don't develop the necessary sensitivities and understandings. Cultural understanding of appropriate behavior which is necessary for communication is difficult to achieve.

The theory of cultural relativism suggests that the individual is a result of his own culture's unique patterns of thinking. Hall (1977) says: "Culture helps us to separate one thing from another." (p.86) "Men cut nature up, organize it into concepts and ascribe significance." (p.123) These significances are relative to each culture. Man's cultural frame of reference is created from his own culture's beliefs, attitudes and values. In other words, culture outlines our way of thinking.

Culture structures the world around us. From birth we absorb the values and significance of the subjective culture and personalize it. Berger and Luckmann (1967) tell us: "the child takes on the significant others" rules and attitudes, that is, internalizes them and makes them his own." (P.281) In other words, our reality and our behaviors are created by our culture when we are very young. They become part of us and develop along with us.

Condon and Yousef (1979) say: "Most of our behavior is 
outside our awareness so that 'normal behavior' means behavior according to the norms of our culture." (p.34) Culture is a silent teacher of acceptable behaviors.

Adler (1976) says: "Culture organizes, integrates and maintains psychosocial patterns." (p.367) Needs are channeled and organized by culture. Culture gets the standards, tells us what we can hope for, and the appropriate methods to achieve and meet our needs.

La Ray Barna (1976) says: "One of the basic functions of culture is to lay out a predictable world in which the individual is firmly rooted." ( $p .294$ ) We need to have some kind of idea of what will happen as a consequence of any action we might take. Otherwise, the risk of participation is intolerable. Culture presents systems of behavior and thought that allow people to communicate.

This short review of the literature shows how important culture is to the development of thought and behavior. Children are especially influenced by culture. Fantini and Weinstein (1968) state: "The culture to which a child is exposed provides him with his education. - mostly through his experiences in that culture." ( $p .9)$ In other words, culture is the child's greatest teacher.

ACCULTURATI ON

\section{A Multi-Dimensional Process}

Acculturation formerly meant the annihilation of 
minority culture. The old assumption of American education was that acculturation, adopting a new culture at the expense of the old one, was a prerequisite to benefiting from American society. In other words, acculturation was thought to be a process of divorcing one's native culture and immediately becoming wed to a new culture, without any looking back. Only then could a person adjust and learn.

Szapocnik, Kurtines and Fernandez (1980) state, "... acculturation has increasingly become a more multidimensional process, with adaptation to a host culture no longer requiring rejection of the culture of origin." (p.354) Effective adjustment requires acceptance of both cultures and ability to live among and interact with both groups.

Teske and Nelson (1974) define acculturation as a process (as opposed to a unitary event) of adapting to new conditions of life. They suggest that acculturation is either a group or individual process involving direct contact in both directions, but not requiring internal change and change in values and reference groups. (p.365) This means that the acculturative process accepts the Individual's cultural identity and introduces it to new patterns without demanding that the old ones be discarded.

Kim (1978) says: "The process of acculturation should be redefined as the process of cognitive, attitudinal and behavioral adaptation to the new cultural system, rather 
than the process of adopting the values of a new society." (p.198) Kim continues to define acculturation as a communicative process, acquiring control over change by learning how to solve problems through communication and interpergonal contact. She suggests three levels of communications patterns that exist in the acculturative process.

The first level is the behavioral level of communication. It requires active participation in the host and ethnic community and mass media involvement. "These two modes of communication behaviors are considered major channels of communication through which immigrants learn, comprehend and develop a more differentiated view of the host society and they develop a certain attitudinal orientation toward the host society." (p.202) Host mass media involvement reflects culture and contributes to the transmission of host society.

The second communication variable Kim presents is the "perceptual (or cognitive) complexity, referring to the degree to which an immigrant's perception of the host society is differentiated, refined and organized into a more sensitive information processing system." (p.200) In other words, perceptual structure helps us to define goals, relate systems, and adjust by the creation of an individual plan of interaction.

The third communication variable is attitude, 
"affective evaluation toward the host culture." (p.200) Attitudes influence perception and interpretation of messages. They influence the way an immigrant behaves in reaction to the host environment.

Based on the powerful role of culture in our lives, as previously discussed, we can assume that acculturation, as defined by Ulibarri and Holman (1980), is "a functioning awareness and participation in two contrasting sociocultures." (p.5) This demands more than a quick change of allegiance.

In American Psychologist (1974) 0lmedo notes three trends in the study of acculturation. First, there is a recent emphasis on ethnicity and ethnic identity, "understanding ethnic groups in their own terms rather than by contrasting them with other culture or reference groups." (p.1062) This allows for a more personalized individual study and respect for human identity. Secondly, he has noted that the study of Individual acculturation has implications for mental health status, cognition, and personality and psychological-educational testing. This supports the trend of thinking about acculturation as multidimensional, Including an "intraphysic mechanism, as change in perceptions, attitudes and cognitions of the Individual." (p.1062) 0lmedo lastly states that a new orientation for the search for measurement of acculturation by psychologists, in addition to anthropologists and 
sociologists exists.

Acculturation is now being studied in terms of sociological, anthropological, psychological and communication models. The multi-dimensional process of acculturation has been identified as a means to study individual and group behavior shared by learning and the interchange of cultures.

Padilla (1980) defines acculturation as a "complex interactional process involving both members of the cultural group undergoing change and members of the host culture." (p.48) Acculturation, in other words, is not a unitary event, but an interaction of cultures. There is a change in tradition and behavior. This change involves both a loss and a gain of knowledge for each cultural group.

Another communication based processual description of acculturation is suggested by Dorothy Sermol, in her thesis, "Toward a Phenomenological-Based Perspective of Acculturation with Application to Scottish lmmigrants," (1983). She states that during acculturation the immigrant needs to learn new behaviors, try out new meanings and explore varying degrees of participation in the host culture. (p.60) These experiences are subjective (the individual's adjusting his culturally trained perceptual field to cope with the perceptual differences in the new culture), relational (the new experiences are interpreted in relationship to the perceptional fleld of self and others 
through communication) and processual.

From a standpoint of psychological adaptation, John C. Berry (1980) states that the individual has several psychological based decisions to make during the acculturative process. Should he retain his cultural Identity? With which group should he Identify? Which behaviors of the host soclety are positive or negative? The course, or acculturative process, in answering these questions is three phased, based on the nature of contact (voluntary or involuntary), the degree of conflict/ resistance, and the stabilization of conflict (adaptation and shifting to the dominant culture in varying degrees). (p.9-11) Acculturation, in other words, is multi-staged, and places many psychological demands on the individual.

Malinowski (1945), a cultural anthropologist, studied societal change and contact. When two cultures cooperate, conflict, or compromise, he used the word "transculturation." This means that there is not a standard dominating all the phases of culture change, but a transmission in which both sides are active, creating a third reality. (p.vii) This idea further supports the trend of thinking of acculturation as an interactive process. This is opposite to the idea of acculturation as being a unitary process, where one's beliefs and values are completely replaced. Acculturation is the development of a third reality for the cultures in contact. 
Charles Marden and Gladys Meyer (1973) identified two levels of acculturation. First, there is external acculturation. This is the behavioral acceptance of the material culture; language and secular roles are acquired. Second, there is internal acculturation. This is when attitudes change. (p.57) Most immigrants are able to acculturate externaliy, but internal acculturation places great demands on the individual. Sampson (1973) suggests that there are "cultural imponderables," elements of a culture that are carried below the level of consciousness, that are very hard to dislodge from thought and behavior patterns. (p.58)

Internal acculturation of cultural imponderables such as linguistic patterns, music style, motor habits and systems of values may never happen. That is why assimilation, a former goal for immigrants and an expectation of a host country, has been replaced by the goal of acculturation in recent years. The major difference between the two terms is that assimilation is, as Teske and Nelson (1974) say, unidirectional, requiring that the newcomer be accepted by the host culture and that the newcomer change his reference group and thought patterns, including his value system. (p.365) Total assimilation is nearly impossible, due to the internal aspects. If people feel that they must assimilate, they will feel confused and guilty. 
Assimilation robs the individual of his native identity. In contrast, acculturation accepts one's native culture as an integral part of his identity. The process of acculturation does not ask an immigrant to change but to adapt and learn at his own pace. He is encouraged to widen his cultural boundaries, but not to replace them as assimilation suggests.

\section{Summary}

Acculturation has sometimes been depicted as a one way process in which ethnic groups surrender their native cultures and conform to host culture practices. This is an unreal expectation - for humans are unconsciously trained by culture from infancy, and it is always a part of them. Locke and Bernhard (1946) sald, "It is generally accepted that individuals reared in one culture and immigrating to another can never be completely absorbed by the new culture. The old culture fades more and more as time goes on, but there is always a residue of habits, ideas and ways of doing things that never completely change." (p.583)

The relationship of man and culture is, as the readings suggest, one of contingency; man is dependent on culture to help him define his reality. As Adler (1976) says: "the center, or core of cultural identity is an image of the self and the culture intertwined in the individual's total conception of reality." (p.366) 
studied has implied that acculturation has the following characteristics:

1. It is a complex process that involves change in two or more individuals or culture groups, whereas both groups (1.e.: student and teacher) can learn and change. It is not one way, and requires interaction and change through direct contact.

2. It is a comprehensive process that sets 1 ts own time clock depending on the individuals involved. This means that acculturation involves the whole individual--how he thinks, communicates, what he believes in, and the degree to which he is able to learn new behaviors and adapt his behavior without sacrificing identity.

3. Teske and Nelson (1974) additionally state that reference group change, Internal change and acceptance by the host culture is not required. (p.365)

For the purpose of this thesis, the following definition of acculturation, developed from the literature reviewed will be used:

Acculturation is the process of adapting to new communication patterns and cognitive and perceptual differences by being able to shift from one's own reality in order to incorporate another reality into one's perceptual system. Acculturation is an interchange of culture, not an attempt to extinguish 
one's own culture; with varying degrees of mental, emotional and psychological participation.

\section{ACCULTURATION AND CHILDREN}

There are specific problems and special needs that school children experience during acculturation. They need to meet the demands of the school, learn to shift from their family's culture and ethnic lifestyle to the reality at school, and learn how to cope with the conflicting value systems of home versus school.

In the classroom where the student must deal with classmates, school rules and cultural differences, something as bastc as recess can be an overwhelming experience. For example, his family may have taught him to learn by observation, the school probably encourages him to speak out and ask questions. The child finds that the traditional values, attitudes and behaviors of his family conflict with those of the dominant society at school. He must learn how to shift between the two realities in order to behave appropriately in each. The lack of ability to adapt on the part of an ESL student obviously can cause problems at school and at home. These problems are all a part of the acculturative process that the ESL students experience. The problems fall into four categories: problems in adapting to the school environment, problems related to language development, ethnicity and identity problems and maintaining 
integrity within the family.

The School

James Dyal and Ruth Dyal (1981) state: "The school is one of the most critical contexts in which acculturation takes place for the children of Immigrants." (p.322) Schools promote dominant society values, attitudes and behaviors, and prepare children to function in the majority culture. For example, most schools in the United States stress Individuality, ownership, competitiveness, curlosity, and reward for personal achievements. The ESL student often comes from a different reality - where traditions include group and family orientations, shared responsibilities, cooperativeness for group success, and the concept of observing rather than asking prevails. Beginning school and surviving in school is often a difficult process. The ESL student, often with little English ability and experience outside of his home, needs to learn new behaviors, develop English competency, meet public school academic requirements and participate in a new and sometimes frightening environment.

Many immigrant children begin their education in Portland with little or no English ability or previous school experience. Joanne Hogden, Student Evaluator and Psychological Examiner of Portland Public Schools ESL/Bilingual Program, has reported that $52 \%$ of enrolling primary school students have an initial rating of 1 , no 
English. These children will spend between five and seven hours (depending on their age) each day at school, making great efforts to understand routines, learn the language and content material while attempting to behave appropriately and develop relationships.

According to Ellis (1980) problems in school include Incorrect grade placement, general confusion about the Amerlcan educational system, the lack of offlclal school records and Identification, language problems, and being caught between the values of home and school. (p.47) He also lists some of the cultural and educational differences that cause problems for ESL students: different order of names, shyness, Intense parental pressures to study more and play less, respect for age, different expectations at home versus school, and passive learning style - resulting in reluctance to ask questions in deference to authority of teachers. (p.14) It is clear that acculturation in school places many demands on children.

Vuong G. Thuy (1979) states: "When the non-English language competent child enters a school where he does not speak the language of interaction, he is overwhelmed and confused." (p.7) There is so much to learn - new social situations, host culture roles and rules within the school, and peer pressures exist. Many children experience a "culture shock" during acculturation. Brislin (1982) defines culture shock as the accumulated stresses and 
strains of being forced to meet one's everyday needs in unfamiliar ways and of the continued need to grope for new behaviors. (p.13)

Due to culture shock, some ESL students remain silent for long periods of time. In fact, teachers are often concerned because the ESL student is non-verbal for the first several months at school. Teachers wonder if the students really do understand what is golng on. Richard Day (1981) suggests an explanation for this silence: "Perhaps silent children are operating under the assumption that anything they say may be held against them. Talking in school could be seen by them as a high risk, low gain situation." (p.38) In other words, adapting to school life is often frightening. There are so many unknowns.

Darlene Durgan, Area Coordinator, ESL/Bilingual Program, Portland Public Schools, has also observed specific behaviors exhibited by ESL students in school when they are frustrated, frightened, or bored. In an oral interview, she stated the following behaviors as symptomatic of ESL student's culture shock in school: a lack of retention or inability to learn, extreme shyness and fear of communication, illness and the desire to stay home, depression, and withdrawal/tuning out. In other words, the pressures in the school to learn English, compete and achieve often have adverse effects on ESL children during acculturation. 
Carl H. Thomas and James L. Thomas (1982) reported that the 1974 Commission on Civil Rights estimated that there were five million linguistically different children in the United States -trying to learn a new language, culture and subject matter simultaneously. This report stated that some chlldren are disiliusioned by school due to the frustration, fallure, rejection and discrimination that they experience. These negative attitudes and fear of fallure often serve as stumbling blocks to learning in school.

Recently, academicians and educators have begun to develop solutions and strategies to help the ESL student during acculturation. R. L. Garcia (1976) studied educational and bilingual programs. In order to help the acculturating student, he has suggested that the school should focus on three humanistic values. First, by accepting the student's home language and giving the student the opportunity to use his native tongue, he will be able to express himself and be less frustrated. Second, it is important to respect the student's culture and ethnicity. Third, by making sure that he feels some success or sense of achievement during the school day, acculturative stress will be lessened. If an effort is made to support the affective domain, the student will experience fewer problems during acculturation.

Frances Willard Von Maltitz (1975) also supports this idea as a means to minimize stress for the ESL student in 
school. He suggests that the purpose of education for minority students is to develop a pride in their own language and culture so they can understand and respect another culture. [See section "Ethnicity and Identity"]

St. Stephens Indian School in Wyoming Wind River Reservation is struggling to preserve native Arapaho language and culture while building academic skills. Administrators report (Instructor, 1985) that: "Efforts to teach Arapaho kids their nearly forgotten language and to Infuse Indian culture into the curriculum, play a crucial role in building self-esteem. Twenty-five years ago, kids were punished for using their native tongues in school. Many kids absorbed the idea that their heritage was to be regarded with shame, denied and forgotten." ( $p .18$ ) Success was assimilation. Currently, st. Stephens School attempts to instill a strong sense of identity and cultural pride in children while at the same time giving them the skills they need to succeed on the outside. This child orientation mixes the best of the Indian culture (Indian home traditions are brought into school) and the best of white culture--so the students can be the best they want to be. (p.21)

Lee Little Soldier (1985) also studied acculturation and children. He states that the home and the school present conflicting worlds. He lists the following teaching strategies to help reduce these conflicts: First, a classroom should have culturally relevant familiar materials 
to help bridge the gap between school and home. Using teacher aides or parent volunteers to give the student a special friend or support system creates a sense of security. Peer tutoring and working in small groups will utilize the strengths of the students whose values include group identification. Respect for the students native holidays, community events, etc. will make the student feel better about himself. Minimizing one on one competition will help the children adfust their expectations. Modeling of appropriate behavior by the teacher will let the student observe what is acceptable. At home they are expected to listen and observe versus asking questions and speaking up. Because of differences in time perspective, teachers should stress short term, present oriented goals. Teachers should also give minority children extra time to reflect before answering a question. Help each child feel success - if academics are difficult, encourage success in art, music, etc.

Alley (1980) suggests that new ESL students need information on the structure of the academic system, how academic performance is graded, rules of behavior for the school and with peers, assistance in conflicts with parents, and ways to share their culture with classmates. (p.112) Understanding the new educational system is often difficult. Schools can help children deal with ambiguities and conflicts during acculturation. Soldier says: "Educators 
who understand the dynamics involved become the enabling agents for the students they interact with." (p.19) An empathetic teacher in a school that supports a culturally diverse student population is the student's connection between the two cultures he participates in. The stress, frustration and conflict that the children feel can be minimized.

\section{Language Development}

Acculturation and language learning are closely linked. As a student acculturates he interacts more, by definition, and therefore he will have more language exposure. Krashen (1982) states: "Second language acquisition is just one aspect of acculturation and the degree to which the learner acculturates to the target language group will control the degree to which he acquires the target language." (p.34) Since acculturation increases contact with speakers of the standard language, Krashen feels the result is that the second language learner will become more comfortable, ready to learn and let language in. He calls this the "lowering of the affective filter." (p.31)

Krashen (1982) also addresses the "silent period," when the ESL student is non-verbal. He states: "Children acquiring a second language in a natural, informal linquistic environment may say little for several months following their first exposure to the second language." (p.26) Over time, children build up confidence by listening 
to and understanding the language around them. Then, they are ready to speak. Krashen calls this the "Input Hypothesis;" speaking ability emerges on its own after enough competence has been developed by listening and understanding .

Robert Dumont (1970) studied the often silent sioux and Cherokee children at school. He provides an explanation for student withdrawal and shyness: "One factor central to many of the problems was language - their inability to speak and understand English very well, which was attributed to parental indifference to education, and the continued use of native language in the home." (p.345) In other words, students learn English when they hear more of it. Students whose families speak in only their native tongues experlence less English "input" and take longer to learn the new language.

Sometimes, teachers incorrectly assume that because their ESL students' English language skills are not developed, their cognitive skills are not developed, too. ESL children with limited English skills are often considered dull or not bright enough to remain on grade level. It is forgotten that in their native tongues, the children are of ten literate and quite knowledgeable. Carl H. Thomas (1982) says: "...refraining from the use of the child's own cultural group language may keep the child from completely and freely expressing all of his thought 
patterns." (p.32) Because of limited vocabulary and English language ability, the ESL student often cannot express himself. Use of bilingual afdes and encouraging native language interaction among students does alleviate some of this problem. Although an emphasis 15 made for the ESL student to learn English, the transition of language skills and expressive ability becomes less stressful and more positive when use of the native tongue is allowed and respected.

Murlel Sarelle and Rudolph Trolke (1971) Jisted the factors that influence second language development as :

1. The nature of the chlld's preschool

linguistic environment.

2. Personality traits of parents and their attitudes.

3. The degree of association with adults.

4. The child rearing practices in the home.

5. The number of siblings and ordinal rank.

6. The attitude of the parents toward their own speech community and toward the second language group.

7. The age of the student. (Research suggests that language acquisition ability declines after puberty.)

8. The motivation of the student.

The common thread that exists among these factors is their affective quality. It is implied that language development is affected most by need, motivation and the psychological environment that exists for each child. 
Positive attitudes, open communication between parent and child and positive feelings of worth of a child will help him to learn a second language.

According to Hoffman (1934), "Language is the most important cultural asset of the human race. It is mankind's most valuable tool." (p.1) It provides the ability to communicate and learn. It also reduces frustration and fallure in school. Vuong G. Thuy (1979) says: "When a child realizes that his educational fallures are primarily due to his being unable to speak and comprehend the language of Instruction at school, he begins to question himself about his capabilities, his background, his home language, his culture... . (p.7) Host language competency plays an important role in the development of academic abilities, self image and positive cultural attitudes of ESL students.

Ethnicity and Identity

Ghais Jasser (1983) states: "The problem of identity is most arduous for the children of immigrants, who are torn between loyalty to the customs and culture of their mother country and those of the adopted land... therapists should help immigrants' children discover and implement their dreams and desires, so that they will not lose their feeling and sensitivity, but create their own identity." (p.12) Educators and therapists are responsible to heip the immigrant child resolve his conflicting emotions and identity conflicts. This would enhance adjustment and 
learning.

ESL students often face the dilemma of not knowing which cultural framework to use as a reference when making a decision in school. They carry with them the ethnic teachings and values of their families, but are participating in a different environment. This ethnic identity confusion affects the student's abilities and attitudes in school. Nedia Moreno Milne (1946) says: "To the extent that his/her language and culture are unacceptable in school, which is a reflection of society at large, the child will suffer a loss of self-esteem." (p.7) Because the positive self-image required for learning is absent, learning can become difficult for the student.

Educators and educational psychologists believe that positive feelings of self worth is necessary for learning. The ESL student brings to the classroom a different set of cultural patterns and he is disconcerted by the culture clash. One clash is that in interdependent cultures like Vietnamese the expectation that children will have an independent self, a self concept, like American children does not exist. Learning and paying attention to the new set of norms becomes a struggle. Ulibarri (1975) says: "If the bilingual bicultural education program does little to develop a more integrated personality and to enhance selfconcept in the bilingual child, it would be better that it not be attempted." (p.11) In other words, fostering the 
development of positive feelings of self worth needs to be a major goal of an ESL bilingual program.

Bruce Gaardner (1967) studied the problems of American Indian children in school. The educational policy had been assimilation, requiring the child to cease being what and who he 1s, and that English be the sole language of instruction. The consequences of this pollcy have been the Indian children's poor self-image and slow achievement in school (as compared to Anglo peers). Gaardner says: "Language and allenation policles have been self-defeating keeping the Indian from self-sufficiency which comes from self-fulfillment." (p.34) In other words, educational expectations of the minority student can be possible when the student begins to feel good about his cultural heritage and traditions and has positive attitudes about himself.

Alan B. Henken and Liem Thanh Nguyen (1981) studied the Vietnamese in America. They say: "While Vietnamese children may speak English, wear American clothes, and behave American at school, at home, in the family circle, they are considered Vietnamese. Their behaviors might appear incongruous to the family circle." (p.51) The result is that the children often feel a cultural statelessness - loss of identity or sense of belonging. Efforts to acculturate in school are often frowned on when carried out at home. [See section on "Family"] Children are often not sure which set of rules and values to abide by. They begin to question 
their identity, and positive feelings of self-worth decline. It follows that learning becomes a struggle.

In a review of bilingual education, Noel Epstein (1978) suggests a philosophy of "affirmative ethnicity." (p.3) This means that the federal government would finance and promote pupil attachments to their ethnic languages and histories while learning English and adjusting to life in a new country. The benefits are two-fold: improving student self-image and learning abilities and the bulling of national language resources while introducing and maintaining other ethnic communities into American society. According to Epstein, encouraging positive feelings in our students is important on an individual and national level.

Alfredo Castaneda (1974) reminds us that our schools, as democratic educational environments, need to be knowledgeable and prepared to teach the culturally different child, who has special needs. We need to consider the preferred mode of communicating, relating, obtaining support, acceptance, recognition and the preferred mode of thinking, perceiving and problem solving of our students. (p.67) By doing so, personal identities and behaviors are acknowledged and respected. It follows, that their education will not be compromised.

Children need to know which culture they are a part of so that they can predict, behave appropriately and be receptive to learning. One integrates from a position of 
strength, not from a position of weakness. During acculturation, cultural identity is not always clear and children often lack a positive self-image and ability to learn.

\section{The Family}

Gordon:(1964) says: "Unlike their parents, many immigrant children are greatly attracted to Anglo-American behaviors. At the same time they are influenced by ancestral culture for primary socialization." (p.25) These children learn how to exist between two cultures. They are no longer a part of the ethnic community, nor are they a part of the dominant society.

Carl Thomas (1982) says: "Children who are in the process of breaking from their parents' culture often feel guilty because they are rejecting family values." (p.31) They have experienced things that they cannot share because the family has stayed in one reality while they have been exposed to another. According to Brislin (1982) families perceive this frustration as rejection, and consequently keep their distance. (p.125)

Communication in the family often breaks down when children are acculturating at a different rate than parents. Locke and Bernhard (1946) say: "Parents whose nationality mores are at variance with what seems to be the pattern of American life at the moment are much distressed by the way in which America, consciously or unconsciously, tends to 
pull their children away from them. In their efforts to pull them back, they often widen the breach." (p.297) Children and parents misunderstand each other's frame of reference, and they become uneasy.

Time magazine, July 8, 1885, devotes a special section to: "Immigrants: The Changing Face of America." Anastasia Toufexis, In his article, "Caught Between Two Worlds," says: "The unusual closeness of immigrant families makes this struggle for autonomy painful for both sides." (p.85) Toufexis describes the conflicting tugs of direction as a constant part of young immigrants lives. He says: "Growing up in two cultures is at once a source of frustration and delight, shame and pride, guilt and satisfaction. It can be both a barrier to success and a goad to accomplishment, a dislocating burden or an enriching benison." (p.84) In other words, children need to learn how "to make a satisfactory amalgam of their two worlds, keeping what they like and discarding what they do not." (p.85)

When a child lives this dual identity, on the periphery of two realities, he is thought of as "marginal." Though having relationships with members of both groups, he is considered an integral part of neither. His loyalties are divided between home culture and host culture. Sermol (1983) says: "The marginality of the immigrant may occur because he feels a need for intra-ethnic support, has acquaintances in both cultures and yet is confused over 
which cultural patterns to follow." (p.68)

Children seem to be very aware of cultural differences Most are interested in trying out host country styles of dress, listening to new music and learning new modes of behavior. Immigrant parents, on the other hand, want the children to maintain native values and traditions while attempting to fit into life in America. Toufexis (1985) says: "Once the critical faculties of the children are sharpened by schooling and broader cultural exposure, however, the gap between them and their parents usually widens." (p.85) The success that the children feel in learning about the new reality that they have been brought to by their parents, separates them from parental mores and values. Children face the paradox of betraying their parents by obeying them.

Summary

Acculturation places many demands on children. It asks them to widen their reality while maintaining native country values and teachings. Adjustment is more than a new language. A child must acquire new concepts, new behavior patterns and develop new emotional ties. Children often question their ethnic identities and personal abilities as a result of their marginal existance.

Ellis (1980) listed the following areas as sources of culture conflict for Indochinese students: 
2. Different rates of assimilation for parents and children.

3. Cultural differences in learning and education.

4. Difficulties in social relationships. (p.15)

Kim (1980) suggests additional problems of young Immigrants include loss of self-esteem, breakdown of the traditional family, the desire but Inability to acculturate, and conflicting and unrealistic expectations of children by parents.

The stress and conflict that chlldren experience during acculturation includes withdrawal/shyness, loss of selfesteem and learning ablitity and the inability to freely express all thoughts. A positive and caring learning environment that fosters an acceptance by the host culture and maintenance of ethnic identity will help a child during this time. If he can develop and maintain an identity that allows him to adapt to new patterns of communication and shift realities, he will be able to acculturate more easily. He will then be able to accept both cultures and have the ability to live among and interact with both groups.

\section{SCALES OF ACCULTURATION FOR USE WITH CHILDREN}

Scales, $1924=\underline{1933}$

To achieve the goal of this study, it is important to discover previous research regarding the linkage between acculturation and academic achievement with two goals in 
mind: What are the previous findings, and do scales exist that could be adapted to this study?

The need to study acculturation and children became clear in the 1920's, when immigrant children came to the East Coast in large numbers. Educators postulated that academic successes and/or fallures were dependent on many variables, including the degree of acculturation of the students. Another wave of immigration to the United States in the seventies encouraged the continued study of acculturation and children.

In 1924, Bere Investigated the association between the language spoken in the home and the ratings on verbal and performance tests of children with non-English parents. He prepared 24 questions relating to language spoken, materials read in the home and questions relative to the social and economic background of a child. His subjects were ltalian, Bohemian and Jewish boys, all ten years old. The children were divided into five groups (a) only foreign language spoken in the home, (b) foreign language predominates, (c) foreign language spoken only to parents, English to brothers and sisters, (d) parents speak foreign language to each other, but English to children, (e) only English used. The results showed that an increase in the use of English in the home is positively associated with an increase in mental age on the stanford-Binet scale and Pintner-Patterson Performance Scale for each of the three nationalities. 
In 1928, Murdoch, Maddow and Berg, studied the relationship between intelligence and the amount of English spoken in the homes of children of foreign-born parents. A questionnaire, consisting of 15 items dealing with the spoken language used in the home was developed. A language scale of nine categories evolved, ranging from "all nonnative tongue" to "all English." The Otis Advance Intelligence Scale (verbal intelligence test) was also given to the children. The results showed that "inherited mental ability is to some degree reflected in the extent to which a family speaks English in the home." (p.351) Decroly (1928) studied the effect of heredity and home environment upon school achievement. His questionnaire was similar to Bere's, but it was answered by parents or instructors. An example question was: "Until what age did the child hear only one language?"

In 1933, Ladd studied English-speaking and foreign language speaking children as to reading achievement. She divided her 315 subjects into three groups based on the answers to two questions:

1. Do your father and mother usually speak English when they talk to each other?

2. Do your father and mother usually speak English to you?

The three groups were characterized as (a) those who spoke and heard English only in the home, (b) those who spoke 
English, but heard their parents speak a foreign language, (c) those who spoke and heard a foreign language. When the English-speaking group was compared with the foreign group, the mean reading age declined as the groups became more forelgn (less English spoken and heard).

Hoffman Bilingual Scale

In 1934, Hoffman designed an instrument to quantitatively measure the extent of bilingual background of elementary school children. The intent was to investigate the problems these children have and the effects these problems have upon intellectual, moral and emotional behavior. Hoffman (1934) asked: "What is the relationship and interrelationship between the extent of bilingual background and intelligence, school achievement, social adjustment, personality, character traits, attitudes and low-economic status?" (p.2)

Hoffman used the term "bilingual" to mean the amount of foreign language background being greater than English language background. He wanted to devise an easily administered instrument for use with elementary school children regardless of nationality or foreign language. The goal was "to provide an accurate quantitative measure of the extent of bilingual environment to which the individual is exposed." (p.10)

The Hoffman Bilingual Scale includes various situations of speaking, reading, writing and listening. Included in 
the criteria were: the items should be of such a nature and so phrased that nine or ten year old children would find no difficulty in giving the information asked for or the questions should afford as objective a response as possible.

The revised Schedule B was administered to 547 children, aged 9 to 15 in four schools in New York City.

The rellabllity of each item was determined by comparing the responses of 25 pairs of children and a second group of 108 children who were given the test twice, with a three week interval.

The validity of each item was determined by finding the Correlation Rates (ETA) between the responses to the item and ratings as to the extent of bilingual background which were obtained for 82 children. ETA was also computed between the responses to each item and the total bilingual score in order to ascertain degree of internal consistency. (p.64)

Hoffman was able to use his measuring instrument to collect data on the relationship between bilingual background and grade status (results indicate practically no association between grade status and bilingual background), chronological age (no association), sex (no sex differences were apparent), non-language mental test scores (extent of bilingual background $\underline{i s}$ associated with verbal adjustment), reading scores and intelligence tests. The differences between the mean intelligence and reading scores of the $25 \%$ 
with the lowest bilingual background and the $25 \%$ with the highest reading scores were compared. The results showed that the degree of bilingual background exerts no influence upon the performance on non-language tests.

Hoffman concludes "The Bilingual Schedule should prove instrumental in securing more precise and crucial results with respect to the effects of bilingual background upon the Intellectual, moral and emotional behavior of an Individual or group." (p.66) He feels that the information collected is useful in understanding the sources of student maladjustment. Hoffman's Bilingual Schedule was later to be used as a framework for the scales and studies to be done in the seventies and eighties.

Qlmedo's Variables

Olmedo (1979) states that acculturation is measurable and multidimensional as Hoffman suggested. He lists the variables used for measuring acculturation as:

1. Linguistic items: language proficiency, preference and use.

2. Psychological variables: cultural values, attitudes, ethnic loyalty and behavior.

3. Socio-cultural indices: education, occupational status, mobility and urbanization.

Olmedo investigated measures of acculturation and conducted several studies before he reached the above conclusions. He studied the relevance of cultural variables 
to psychological and educational assessment in two separate studies.

In the first study (01medo, 1978), he developed an "acculturation inventory" that would provide a quantitative measure of acculturation for Chicano adolescents. The instrument consisted of a two-part inventory. The first part consisted of Semantic Differential Potency items. The second part consisted of 18 items covering background information: the family, language spoken, occupational status. The two sets of varlables were called "semantic variables" and "sociocultural variables." The acculturation score for a given individual was defined as the sum of the varlables that had been weighed according to a regression coefficient and a constant.

On his second study (1978), he replicated the instrument previously developed with different subjects, compared acculturation scores between first and third generation Mexican-Americans, and established the relationship of acculturation to sociocultural characteristics such as education, ethnic selfidentification, religion, household type and occupational status. Results were as follows:

1. Language is a prime indicator of acculturation and degree of ethnic group membership.

2. Acculturation levels are lowest for first generation Mexicans (as expected). 
3. Individuals who scored lower in acculturation have greater native ethnic identity, live in nuclear households and have lower educational and occupational levels.

Olmedo was able to measure acculturation and further define the variables that affect $1 t$.

Padilla's (1980) theoretical model of acculturation postulates that acculturation is dependent in the two major dimensions of Cultural Awareness (CA) and Ethnic Loyalty (EL). He used 136 items when working with Mexican-American children and performed a primary factor analysis that yielded four factors for each dimension. The strongest factors for the CA dimension were the subject's Spanish language familiarity, cultural contacts and ethnicity of peers. The EL dimension's strongest factors were language preference and use and social behavior of a Mexican orientation.

Padilla's study confirms previous research that acculturation is a complex process, with language usage playing a major role.

Franco's Child Acculturation Scale

In 1983, Juan Franco developed an acculturation scale for use with Mexican-American children. It was created to study the problems that Mexican-American children have during acculturation and the effects these problems have on behavior. By identifying a child's level of acculturation. 
based on the degree to which a child has adapted to mainstream socio-cultural behaviors, Franco hoped to pinpoint the behaviors or the lack of certain behaviors that were causing problems.

The Child Acculturation Scale (CAS) is completed by a teacher, parent, counselor or anyone who knows the student well. It is a 10-item Likert-type scale requiring the person filling out the instrument to respond to ten items on a one to five point scale. Franco's CAS was selected for measuring individual child acculturation levels in this study. A complete description of the CAS follows in the section "Measuring Instruments."

In 1984, Martinez, Norman and Delaney developed and tested the Children's Hispanic Background Scale modeled after Hoffman's (1934) scale. The CHBS consists of thirty items estimating exposure to Hispanic culture and extent of communications in Spanish. Low score represented high Hispanic cultural exposure and low Anglo acculturation, and high scores the reverse. The results were similar to those of Franco. The major primary factor correlated highly with the English proficiency of the child. The language spoken at home, his/her language preference and his/her own identification preference.

\section{Summary}

The scales reviewed in this chapter are a result of this identified need to study the acculturation process of 
children. All of the scales have the following salient characteristics:

1. They are designed for use with children - the language is clear and simple, the tests are short and easy to understand.

2. They have considered semantic, psychological, and socio-cultural variables.

3. They have recognized that an ethnic group is heterogenous, not necessarily homogeneous, due to the different acculturation levels of its members.

4. They have recognized the fact that degree of acculturation of a child can effect school adjustment and achievement.

5. They propose that an understanding of a child's acculturation level will help teachers provide better directed and individualized instruction and that teachers will have greater insights in regard to students' psychological and emotional adjustment problems. 
CHAPTER III

DESIGN OF THE STUDY

\section{PURPOSE}

The major purpose of this study is to determine if a correlation exists between an ESL student's degree of acculturation and his achlevement in reading, math and English.

The relationship that exists between child acculturation levels and academic achievement has been discussed often in the literature but has rarely been empirically tested. Perhaps this is because appropriate measuring instruments have not been discovered. Therefore, a secondary purpose of this study will be to determine if a children's scale of acculturation exists that can be a useful tool for research and for educational assessment. 
HYPOTHESES

Theoretical Hypothesis -

ESL students with a high degree of acculturation have greater academic progress and English gain than students who have a low degree of acculturation. This general hypothesis has been broken down to study three sets of variables.

Null Hypothesis I - Acculturation level and reading gain are independent.

Alternate Hypothesis I - Higher reading gains occur with higher acculturation levels.

Null Hypothesis II - Acculturation level and math gain are independent.

Alternative Hypothesis 11 - Higher math gains occur with higher acculturation levels.

Null Hypothesis III - Acculturation level and English IDEA level gain are independent.

Alternative Hypothesis III - Higher English IDEA level gains occur with higher acculturation levels. 
DEF INITIONS

Acculturation has been defined as the process of adapting to new communication patterns and cognitive and perceptual differences by being able to shift from one's own reality in order to incorporate another reality into one's perceptual system. (see p. 16)

The literature review has suggested the following variables that effect the acculturative process:

1. Linguistic variables: the degree of English spoken in the home among family members, the reading materials available, the language of social Interactions and entertainment.

2. Ethnic Identity variable: to which culture does the child identify?

3. Socio-cultural variables: the degree to which the child is participating in each or both cultures.

Since these variables are so commonly identified, it seems reasonable that they should be included in any acculturation scale. 
MEASURING INSTRUMENT FOR ACCULTURATION

An important part of this study is to design or select a measuring instrument to determine individual student levels of acculturation.

Criteria for Measuring Instrument

Before searching for an instrument

the following criteria were established:

1. The scale needs to be designed specifically for use with the immigrant child who is acculturating to life in school and a different cultural environment.

2. The instrument needs to be able to be completed by an adult as the children do not have the necessary reading and comprehension abilities to complete and understand a questionnaire. (An oral questionnaire would not be appropriate because students would have difficulty understanding the questioning, concepts might not be totally understood and too much class time could be needed to administer.)

3. The instrument should identify the degree to which acculturation has been reached. The literature review has identified three components that should be included when measuring acculturation: the instrument needs to include linguistic, ethnic identity and socio-cultural variables that effect acculturation.

4. The instrument needs to provide a score, based on 
a continuum, indicating level/degree of acculturation of a child for ease of statistical analysis.

Selection of the cas scale

After a careful review of the scales developed to test acculturation in children, it has been determined that Franco's (1983) Child Acculturation Scale (CAS) is best suited for replication in this study. There are several reasons that support the use of this instrument and its ablitity to meet the previously determined criteria.

First, the CAS was designed for use with children to assess degree of acculturation based on a continuum of acculturative behaviors. This supports the idea that acculturation is a process as opposed to a yes-no, blackwhite theory of behavioral change, and meets criteria \#5.

Second, the CAS was developed by Franco to include the variables that affect acculturation: language use and familiarity (linguistic variable), ethnic interaction (socio-cultural variable) and food and entertainment preference, religion, education, parental occupation (ethnic identity variable). By addressing these variables, the scale meets criteria \#3.

Third, the scale is to be completed by an adult. This eliminates misunderstanding on the part of the child, the need for parental approval for questioning the child, and the use of class time. This meets criteria \#2.

Fourth, the CAS has been proven valid and reliable for 
the purpose of determining a child acculturation level. (See description of the CAS, p.48)

Fifth, although the CAS was designed for use with Mexican-American students, it is easy to substitute the term "native ethnicity" when completing the questionnalre. These 1tems are then applicable for use in this study.

Sixth, the CAS was developed because chlldren were having problems in school during acculturation. It was hoped that the scale would provide detalled information about a child's acculturative progress. This information would encourage a greater understanding of why the child is experiencing academic problems. This meets criteria \#1.

Description of the Child Acculturation Scale (See Appendix A)

The following dimensions, derived from literature reviews, communication experts and other scales were chosen by Franco as being related to acculturation: language familiarity and usage, ethnic interaction, religion, education, parental occupation, food and entertainment preference. Franco attempted to include these variables in the CAS.

Since many of the children did not have reading skills, Franco developed an instrument that could be completed by an adult who knew the children well. An adult rater is also appropriate as many children have trouble making decisions and understanding the relevance of adult questioning. 
A 10-item Likert-type scale which required the person filling out the instrument to respond on a one to five scale was used. The CAS takes five minutes to complete. The rater needs to base his/her answers on factual information, but some items require the rater's opinion, for example: the chlld's preferred ethnic identification. The rater circles, after thoughtful judgment, the answer between one and $f$ ive that best fits the question. The total score is the sum of the responses to the 10 multiple choice 1 tems. The acculturation score equals the mean response, $1 . e .:$ the total score divided by the number of items answered. The acculturation score ranges from 1 to 5 ; the higher the score the more acculturated the individual.

Retest reliability was determined by giving the test on two separate occasions to 14 children by the same evaluator. The correlation (coefficient of stability) was .97.

Three techniques were used to determine construct validity, that is, the extent to which the test actually measures a theoretical construct--such as acculturation. First, it was correlated with another acculturation measure, the Acculturation Rating Scale for Mexican-Americans. Secondly, the CAS was factor analyzed and thirdly, a comparison was made, comparing first, third and sixth grade scores. It was hypothesized that students with more education who were increasingly involved with American institutions would have an increase in acculturation scores. 
Franco (1983) states that "acculturation occurs along a number of different planes" ( $p .179$ ) and that the 10 items in the CAS do not tap all of the components of acculturation. However, three factors among children are identified:

1. Language proflciency, usage, preference and peer associations and identification

2. Parental occupations and educational level

3. Music preference

The CAS "Is sensitive to changes in the individual as he or she progresses through the educational system and has potential for use in assessing individual levels of acculturation." (p.180)

\section{OTHER MEASURING INSTRUMENTS}

Portland Public Schools measure growth in academic achievement twice yearly with the Portland Achievement Levels Tests (PALT) which are directly related to the Portland Public School Continuum. The Continuum is designed to build academic skills. The PALT are graded by two scores: the P-Score (the average mean when compared to all students in Portland District) and the RIT score (individual student performance based in grade level curriculum). The tests have been proven reliable and valid by Portland Public Schools Evaluation Department.

The gain in RIT Score from the Fall of 1984 to the Fall 
of 1985 will be used in this study. These are the most recent scores available. Increase in RIT scores indicate individual academic progress in a given area. RIT scores are posted yearly in student permanent flle folders located in each school. RIT scores in math and reading will be used as these are the only valid and reliable scores currently available for ESL students grades 3 to 5 .

English gain for this study will be calculated by the growth of levels in the IDEA Program (Indlvidual Developmental English Activities) used by ESL teachers. The IDEA Student Profile (see Appendix B), forms a continuum of elght levels of English skill competency that ESL teachers use as a framework for curriculum and to record and measure progress. Students begin at Level I, and as they master language skills they move up the continuum to higher language levels. ESL teachers in Portland Public Schools use the IDEA Program as recommended by the ESL/Bilingual Department. It combines oral and written language skills development based on integrating activities (games, art). The IDEA Program also allows students to progress at their own rate and teachers to plan for and test each child individually. The IDEA Profile is accepted as a valid and reliable test of English proficiency. 
METHODOLOGY

Qverview

In order to study the relationship between the degree of acculturation and achievement and English gain in school the following procedure w1ll be followed:

1. The Child Acculturation Scale will be administered to 32 ESL students, aged 7 - 11 to determine individual levels of acculturation.

2. Achievement growth (Fall, 1984 to Fall, 1985 Reading and Math) in PALT scores (Portland Achievement Level Tests) and gain in IDEA levels (English language) will be collected.

3. A measure of rank correlation, using spearman's Rho measure of correlation, between individual acculturation level and academic growth in reading, math and IDEA English gain will be determined.

\section{Population}

In order to complete this study, subjects were needed at one location, where student records were available and the ESL teacher was able to respond to the CAS questionnaire with confidence. Beach Primary School fit this criteria and was selected for the study.

There are a total of 57 ESL students attending Beach School. Not all would fit the requirements of this study; therefore, it was necessary to specify sample criteria. An 
effort was made to confine the students to a specific age and economic level as well as be sure all students in the sample had not progressed beyond the acculturation process.

Criteria for selecting the Sample

Thirty-two ESL students at Beach Primary School were selected for use in this study. They are of various ethnic backgrounds: Vietnamese, Cambodian, Hispanic and Polish. This multi-cultural mix is fortunate in that it avolds making generalizations about specific ethnic groups as that is not a purpose of this study.

The students:

1. Must be born in another country and be between 7 and 11 years old.

2. Speak a language other than English in the home (as indicated by Portland Public Schools Registration form).

3. Qualify for free and reduced meals at school (this program is available to children of low income families). This limits sample to students of same socio-economic level and controls variables of economic difference.

4. Attend ESL class which signifies they would likely be in the process of acculturation adapting to life at school and learning how to maintain appropriate behaviors both in their homes and at school.

5. Be enrolled in grades 2 to 5 with reading and math 
PALT scores recorded in permanent folders.

\section{Procedure}

Administering the CAS - The CAS will be administrated by an adult who knows the children well. The children are only indirectly involved. There are several advantages to this. First, it eliminates confusion, misinterpretation and time consuming explanations that are involved when directly questioning children. Young ESL students especially have trouble giving their opinions and making decisions. Second, a single judge eliminates the need for inter-rater reliability. Third, no classroom instructional time is used.

In this study, the CAS will be administered by the students' ESL teacher. Student-teacher relationships over the past two years have allowed her to be prepared to answer the questionnaire about each child; an ESL teacher is close with her students, also serving as a student advocate, counselor and friend. This allows her to be quite knowledgeable about each student's academic progress/problems, home 1 ife and relationships at school.

Portland Public Schools has approved this study, which involves collecting test scores from students' permanent file folders. Test results will be catalogued by giving students" identification numbers; no names will be used; confidentiality will be maintained. 
Comparison of the PALT and IDEA Score Gains with Acculturation Level - Three types of statistical procedures were considered for measuring the correlation between PALT and IDEA score gains with acculturation level. The most commonly used measures of correlation is Pearson's product moment correlation coefflcient. This measure is significant when the distribution of variables is known. In this study, this distribution of variable $Y$ (acculturation level) is known but the distribution of scores of variable $X$ (math, reading or IDEA English gain) is not known. Therefore, Pearson's product moment correlation was not acceptable for use.

Also considered were Kendall's tau and Spearman's Rho. Both are based on the order (ranks) of observations rather then numbers themselves and the distribution of the measure does not depend on the distribution of $X$ and $Y$ if $X$ and $Y$ are independent and continuous.

The measure of correlation selected for use in this study was the Spearman Rho. The Spearman rank correlation coefficient is often used as a test statistic for independence between two random variables. An explanation of the statistical representations as they are used in this study follows. 
Spearman Rho Formula

$p=$ measurement of correlation

$X_{i}=$ reading, math, or IDEA gain

$R(X i)=$ ranking of reading, math of IDEA gain

YI = acculturation level

$R(Y I)=$ ranking of acculturation level

$$
P=1-\frac{6 \sum_{i=1}^{n}[R(X i)-R(Y i)] 2}{n(n-1)}
$$


CHAPTER IV

F IND INGS

\section{DEGREE OF ACCULTURATION}

The possible score for degree of acculturation in the Child Acculturation Scale (Appendix A) ranges from 1 to 5,1 being the least acculturated and 5 , the most acculturated.

In this study, students scored from 1 to 2.5. The average score was 1.56. For most of the students, the native language is preferred and is used in the home (Items \#4 and \#5), the child prefers to be identified by his native ethnic group (Item \#6) and prefers to interact with his native ethnic peers (Item \#7) (as opposed to American children). This preference of native linguistic, ethnic and socio-cultural variables could account for the low individual acculturation levels of students within the range of this scale.

It also must be noted that these children are children of refugees, they are not yet American citizens (Item \#10). Previous research (0lmedo and Padilla, 1978) reports that degree of acculturation does increase with each new generation born to immigrants and that the third generation has a higher degree of acculturation. For additional discussion of the findings, see p.66. 
COMPARISON OF PALT AND IDEA GAIN WITH ACCULTURATION LEVEL

Acculturation Level ys. Reading Gain

Fifteen students' PALT reading gain scores from Fall

' 84 to Fall' 85 were correlated with their individual scores of acculturation (see graph p.57) (PALT reading scores are only avallable for students in grades 3 to 5 which accounts for the low sample sizes. Acculturation levels of the students ranged from 1.3 to 2.5 within a distribution of 1 (least acculturated) to 5 (most acculturated). Reading gain ranged from 0 to 13 points. Students with higher acculturation levels (above 2.0) tended to have greater reading gain. Students with lower acculturation levels tended to have less gain in reading achievement.

Null Hypothesis I - Acculturation level and reading gain are independent.

Alternative Hypothesis 1 - Higher reading gains occur with higher acculturative levels.

Test statistic $-(\alpha=.10$ - chance of error of rejecting null hypothesis when true) $n=15$ (PALT scores available only for students, grades 3 to 5 )

Spearman's Rho $=1=\frac{6}{15} \frac{(409)}{(15.15-1)}=.270$

$p=.270<.35=.90$ quantile 
Conclusion: Data presents a positive, though not statistically significant, association of reading gain and acculturation level. 
GAIN

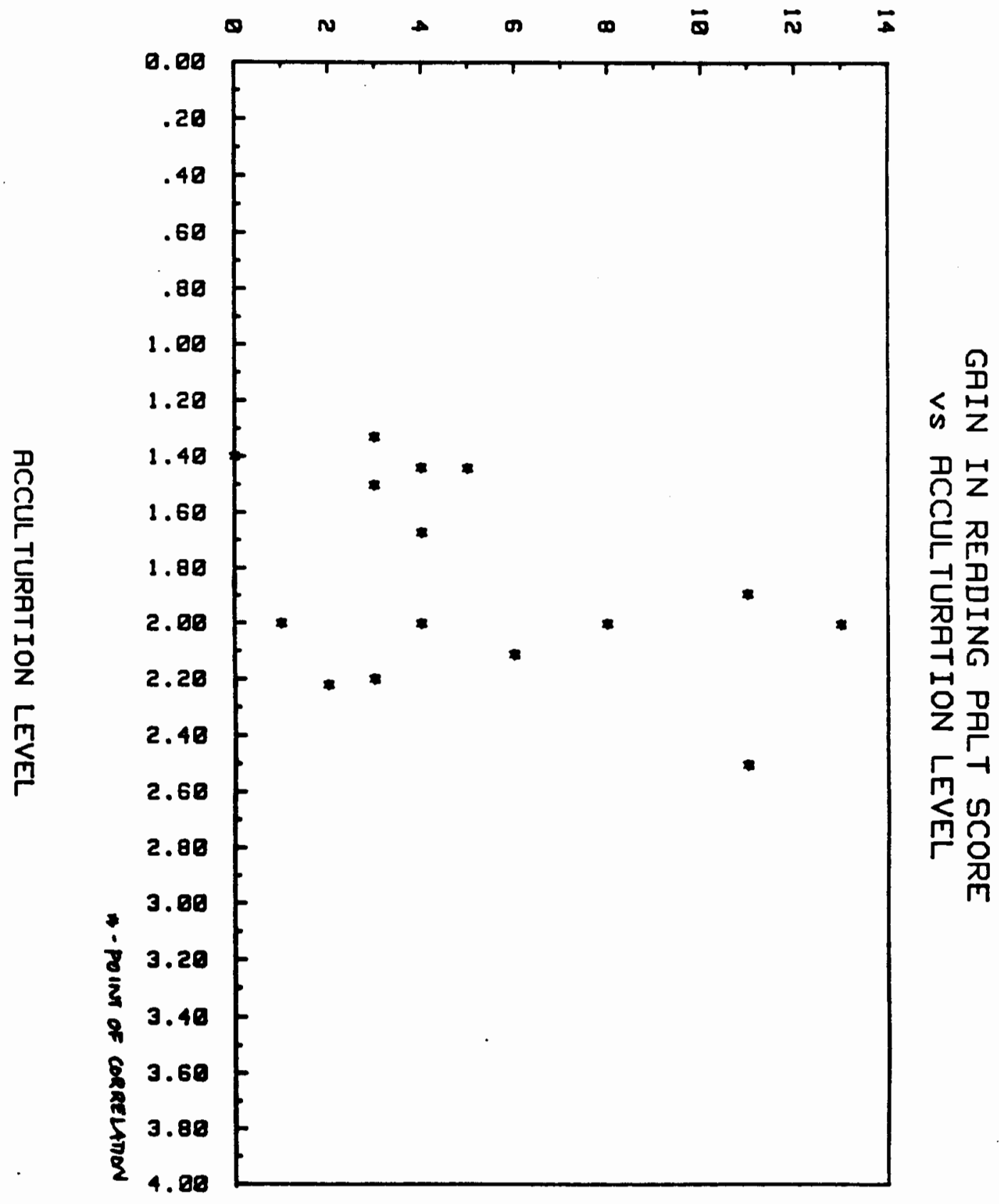


Acculturation Level vs. Math Gain

Fifteen students' PALT math gain scores from Fall '84 to Fall' 85 with their individual scores of acculturation. (See graph p.59) Acculturation levels of the students ranged from 1.3 to 2.5 within a range of 1 (least acculturated) to 5 (most acculturated). Math gain scores ranged from 3 to 12 points. Students with greatest math gains ( 7 to 12 points) tended to have higher acculturation levels (above 1.9 ).

Null Hypothesis II - Acculturation level and math gain are Independent.

Alternative Hypothesis II - Higher math gains occur with higher acculturation levels.

Test statistic $(\alpha=.10$ - chance of rejecting null hypothesis when true)

$n=15$ (PALT scores available for students, grades 3 to 5 )

$$
\begin{gathered}
\text { Spearman's Rho }=1-\frac{6(243)}{15(15-15-1)}=.566 \\
p=.566>.518=.975 \text { quantile }
\end{gathered}
$$

Conclusion - Higher math gains do tend to occur with higher acculturation levels and lower math gains with lower acculturation levels. 


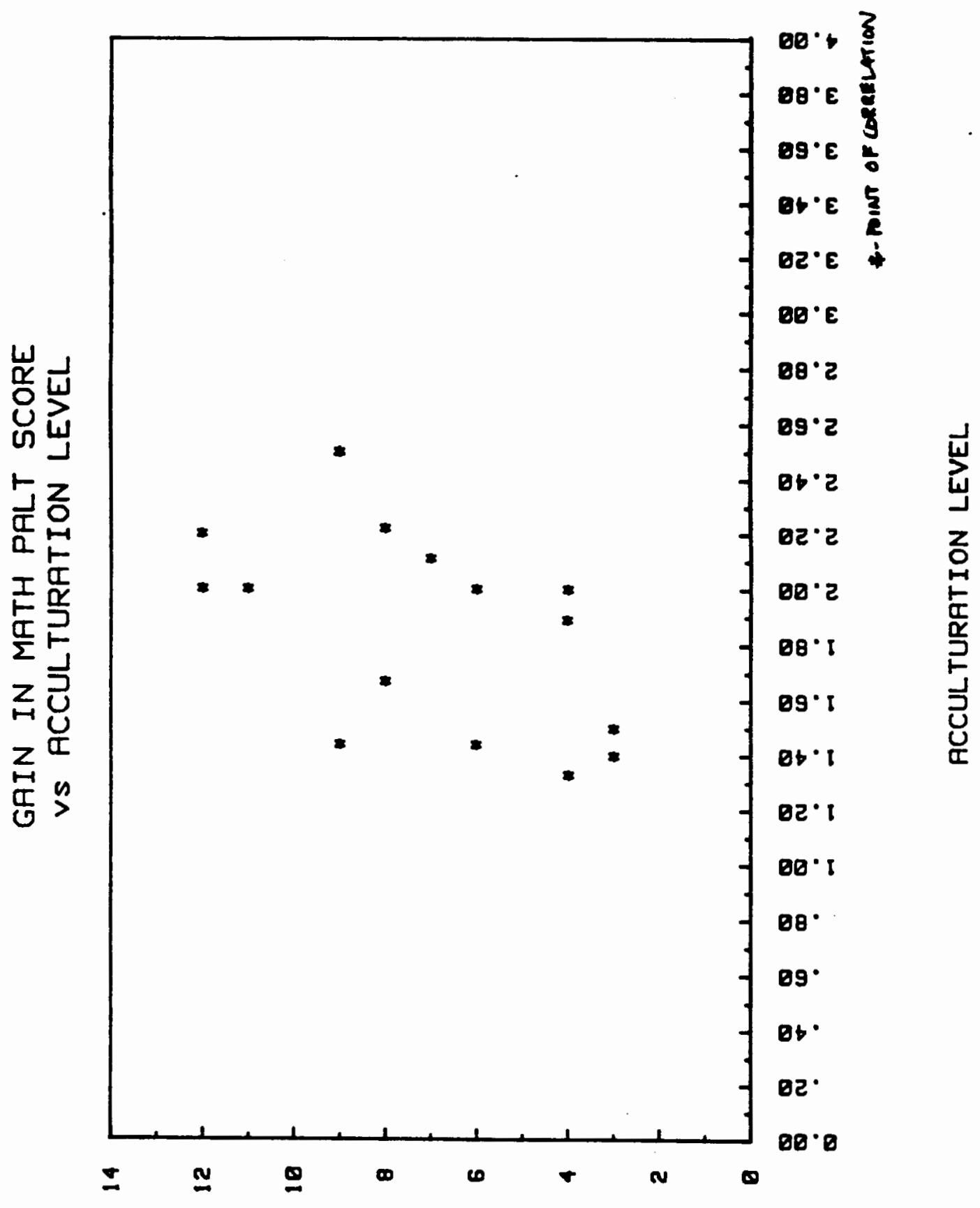


Acculturation Level vs. English IDEA Level Gain

Thirty-two students, IDEA (English language) levels gain (Fall '84 to Fall, 85) were correlated with their Individual scores of acculturation. (See graph p.61) Acculturation levels of the students ranged from 1.0 to 2.5 on a range from 1 to 5. IDEA gain ranged from 2 to 5 levels. Students with the greatest gain in IDEA levels tended to have higher acculturation scores.

Null Hypothesis - Acculturation level and English IDEA level gain are independent.

Alternative Hypothesis - Higher English IDEA level gain occur with higher acculturation levels.

Test Statistic $-(\alpha=.10$ - chance of rejecting null hypothesiss when true)

$\mathrm{n}=32$

$$
\begin{gathered}
\text { Spearman's Rho } \left.=1-\frac{6(2365)}{32(32.32}-1\right)=.566 \\
p=.566>.5479=.999 \text { quantile }
\end{gathered}
$$

Conclusion - Higher English IDEA level gains tend to occur with higher acculturation levels. 


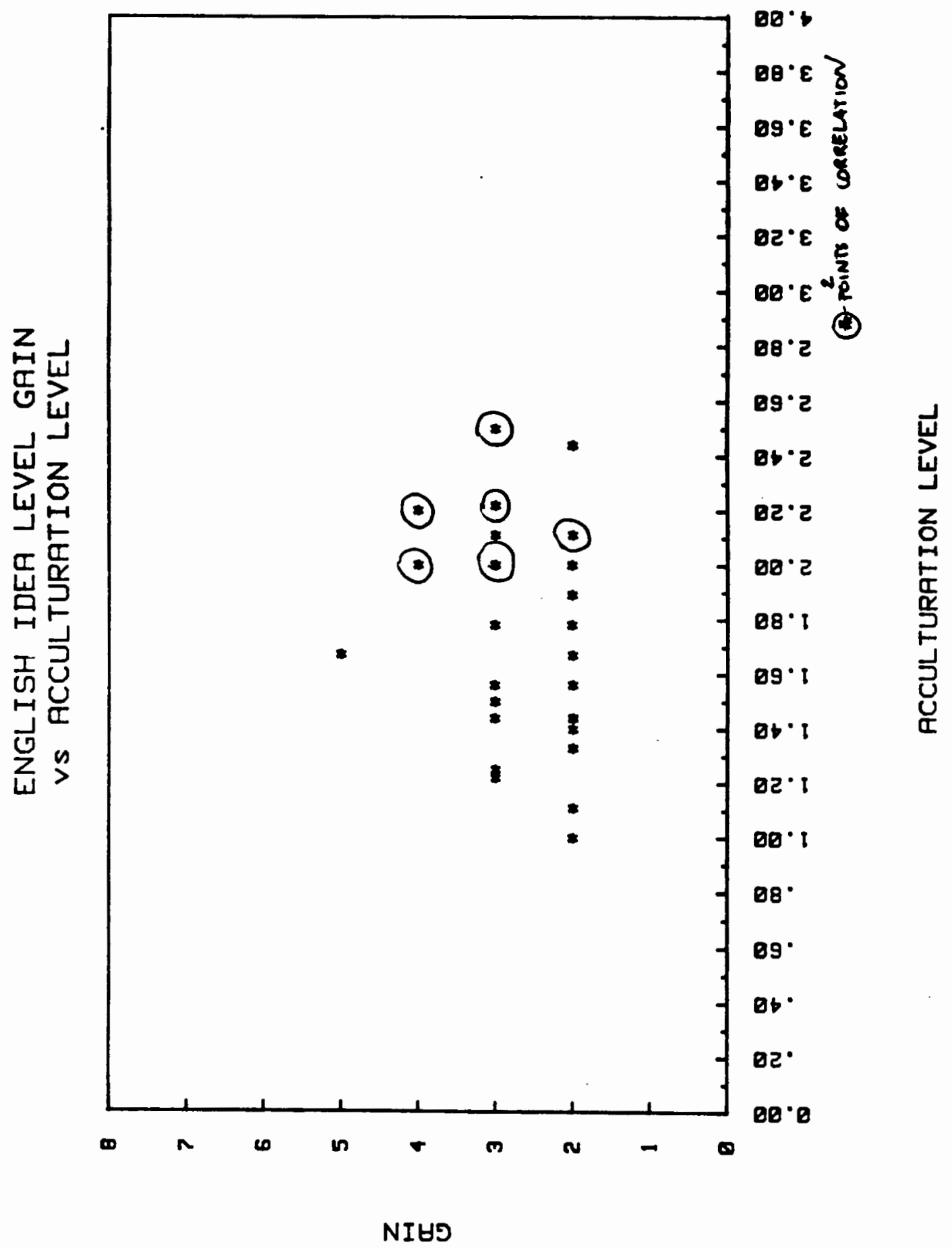


CHAPTER V

DISCUSS ION

\section{INTERPRETATION OF THE FINDINGS}

The findings from this study support the theoretical hypothesis that ESL students with a high degree of acculturation would have greater academic progress in math and English gain than students who have a low degree of acculturation. There was a positive, though not statistically significant correlation with reading.

By definition, students with a high degree of acculturation have better adapted to the school environment than students with low acculturation levels. By understanding routines and appopriate behaviors and responsibilities in the school (however different these may be from their native school environs) and by adapting to the American learning style las opposed to continuing native classroom expectations and learning style), students with higher acculturation scores have become more receptive to learning and in turn would be likely to have experienced greater achievement and academic progress.

Students with higher degrees of acculturation have also learned how to adapt to the different lifestyles between the school and their homes. In other words, by having an 
understanding of the two realities and what each expects of them, the children are aware of the appropriate behaviors necessary to participate in both with a minimum of personal stress. An example of this would be the child's realization that asking questions in school is appropriate behavior and begins practicing this skill. As he becomes comfortable doing this, he can get information he needs to improve his assignments. Yet, in the home, he does not question his parents for fear of reprisal.

Students with higher degrees of acculturation have also begun to associate with non-native or American peers (CAS Scale - Item \#7). This has several advantages for them socio-culturally and academically. First, children learn from their peers. When the ESL student develops friendships or associates with American peers, instead of limiting his associations to ethnic peers, he is increasing his knowledge of American culture. He is able to learn new behaviors (although some may not always be positive from an adult's standpoint) by experiencing rather than observing. By participating in the American culture with his peers, the ESL student better understands and enjoys it. American traditions become less foreign and more acceptable. An example of this would be recess behavior that this author has observed. Many ESL students eat lunch and play at recess time only with their native peers. Their jump rope game is exclusive of American children. On the other hand, 
there exist a few ESL students who do play softball, kickball or basketball with American peers. These students have begun to broaden their cultural boundaries. This, in turn, would give them confidence and make them better able to participate in learning tasks.

Hypothesis I: Acculturation vs. Reading

There are several reasons why the more acculturated ESL students' scores have a positive correlation with reading gain. By associating with American peers, the ESL student has the opportunity to use his developing English skills in real-life situations. Besides improving his communication abllities, the student begins to think in English, become more comfortable with his English abilities and, in turn, improve his language skills as they relate to other academic areas. It follows that he is better prepared for reading. By developing confidence as a result of successul communications with American peers, the ESL student is more apt to experience greater reading development by having increased his vocabulary. Also, it should be noted that the sequence of English mastery is often accepted as listening. speaking, reading and writing. When a student is more acculturated and can communicate orally, he is therefore more ready to read.

The ESL student who has developed friendships with American children has the opportunity to participate more in after school activities that reflect American culture. 
Whether it be visiting an American child's home to play after school, or joining the cub scouts, the ESL child broadens his cultural understanding through interaction. (The same holds true for the American child!) This Increased Interaction with the Host culture can also help to Improve reading abllity as the student is less affected by culturally biased materials (his cultural awareness has increased) and he has developed an ability to predict appropriately. Also, his comprehension ability is increased because of Host cultural understanding.

Another explanation for the positive correlation between the more acculturated student and his gain in reading ability is that the more acculturated student probably has had more exposure to written materials since the educational level of the head of household is higher than in the home of the less acculturated child. (CAS, Item \#8)

Hypothesis II: Acculturation vs. Math

There are several factors that could explain why the more acculturated student has greater math gain than the less acculturated student. As the process of acculturation has been shown to be multi-dimensional, much of the discussion in Hypothesis I is also applicable here, but there are other factors that are specifically math related. Additionally, the more acculturated student, by definition, is adapting to life and school and at home. He is taking 
chances to learn and grow at school. This gives him the opportunity to practice his math skills within the school environment. He learns how to use a lock with a numerical system, count money, use a calendar; and he participates in the "hands-on" math curriculum, in most classrooms. He does not need great language skill to achieve in math, but he needs confidence in order to use and develop what he has learned. It follows that the more acculturated student who has positive feelings of self-worth is able to take risks using his math skilis in practical, often non-speaking situations.

Number systems and mathematical processes are almost universal. It follows, then, that the student is able to transfer skills already learned. Additionally, math is a subject with which the more acculturated ESL child's parents might be able to help him (Educational level of parents parents higher than in the less acculturated student's home).

Also, achievement in math is often dependent on how much the student practices and the accuracy the student develops. Many ESL students spend countless hours on math worksheets - a solitary activity that rewards them with success and positive feelings of self-worth.

Hypothesis II: Acculturation vs. IDEA English Gain

It must be noted here that one quarter of the CAS actually measured linguistic variables. The ESL student 
with a higher degree of acculturation had greater English proficiency (Item \#1), hears English in the home to some degree (Item \#4) and prefers to use a mixture of his native language and English (Item \#5). This could explain the high correlation between IDEA English gain and acculturation the two processes are closely linked. Children learn language through culture and culture through language. Schumann's Acculturation Hypothesis (1978) supports this 1dea: "acculturation is the mafor causal variable in second language acquisition." As previously reported, students learn English when they hear more of it. It follows then, by reason and by definition, that the student with a higher degree of acculturation will have greater English gain. He is interacting with the Host culture and is more apt to learn the language.

The more acculturated ESL student has also overcome culture shock and has learned how to integrate the two cultural realities he participates in. It is also possible that he has passed the "silent period" (see Krashen, p.23) and has minimized stress and let language in.

\section{Conclusion}

It seems appropriate to this author that acculturation has proven to be a factor in ESL student achievement and academic progress. Culturally diverse children enter school with behaviors that differ from the cognitive and social norms that teachers expect. As the children acculturate and 
their behavior is less discrepant from the norms of the school, they experience a feeling of personal efficacy. It cannot be assumed, however, that low acculturation is the only factor in low achievement. Other factors such as health, I.Q., etc. could be influential but are beyond the scope of this study. It has been shown, though, that a student who is acculturating has begun to understand linguistic cultural and identity differences between cultures through interactions with the Host culture without gacrificing personal identity. He has opened his cultural boundaries and is ready to learn.

\section{LIMITATIONS OF THE STUDY}

There were several limitations of the Child Acculturation scale discovered after using it in this study. As evidenced by the narrow range of acculturation levels scored by students, there is a possibility that parts of the scale were not specific enough for use with these children. Father's occupation (Item \#2), mother's occupation (Item \#3), educational level of head of household (Item \#8) and child's citizen status (Item \#10) could easily be predicted as scoring low due to the refugee status and socio-economic status of these children. The scale did not address which code of behavior the student followed, types of problems he experienced or his perception of the treatment received by the Host culture. 
Since all the acculturation levels fall into a small range $(1-2.5)$, there is also a possibility that the scale needed to be more discriminating in defining acculturation variables. For example, there was no consideration of the child's previous education, length of residency and his/her rank in the family order. These variables might also affect acculturation as reported by Sarelle and Trocke (1971), 01 medo and Martinez (1978) and Martinez, Norman and Delaney (1984). The five point scale (versus a seven point scale) also restricted differentiation from being more finely tuned.

Another possible limitation of the CAS was that it emphasized oral language without consideration of written language (Item \# 1 - English proficiency, Item \# 4 language spoken in the home, Item \#5 - language child prefers to use). There was no consideration of reading abilities or of reading materials (in English or native language) in the home. Whether or not this is a factor in acculturation is yet to be determined.

Limitations of the study also included the small sample size, the limitation to one school and the fact that PALT scores in reading and math were not available for the younger students. These factors restricted analysis, validity and other possible significant findings. The reliability of the CAS scale is also under question since the test re-test was restricted to a small sample size. 
SUGGESTIONS FOR FURTHER RESEARCH

It was a secondary purpose of this study to generate or discover an acculturation scale for children. The need for another specifically designed scale to identify acculturation levels of children has become apparent. This is because of the limitations of the cAs scale, as previously discussed and the other child acculturation factors identifled in the literature review. A scale with a larger number of items that reflects these additional factors as they affect a child's acculturation process is needed. Other problems with this scale were specifled under limitations of study.

Since the sample size in this study was relatively small, further research on acculturation and its relationship to academic gain could be done with a larger sample that would be more reflective of the large body of ESL students in our schools. The present study, involving students at one school, does not necessarily reflect what could be going on elsewhere.

Additional research on acculturation and children could explore other issues of acculturation of interest to the educator such as the relationship between acculturation and age, acculturation patterns of different ethnic groups, the effects of differing levels of acculturation within a family and acculturative differences between males and females.

A follow-up study is also suggested to measure 
acculturation of the same students a year from now and compare it with achievement. It would be interesting to note the change in acculturation levels, academic progress and any pattern in acculturation. How much has length of residency, change in family status and Increased English usage in the home affected acculturation and academic progress? 
CHAPTER VI

APPL ICATIONS

There are several sallent applications of the literature review and results of this study. The information and results presented in this study could be used to better educate classroom teachers and administrators. Anyone who works with ESL students could be enlightened, Informed and perhaps develop more realistic expectations of their students and their students' needs as a result of this knowledge.

Since it is clear that acculturation is positively correlated to academic achievement in math, reading and English, it is important that needs of an ESL student in this regard must be a primary consideration of educators. Low acculturated ESL children have specific emotional and psychological needs that demand special attention in school. Research has determined that these needs are a part of the acculturative process and that, therefore, they are a factor in academic achievement and English gain.

It would be beneficial for teachers to use a measure of acculturation to help identify those likely to have difficulty academically. Many times, the lack of, or slow progress of an ESL student causes frustration for the classroom teacher who cannot figure out why certain 
students, problems exist. If the teacher was able to see and understand where a student placed on a continuum of a scale of acculturation," he would possibly have greater Insights relating to the cause of problems and be able to develop appropriate teaching strategies and expectations. If a problem student showed high acculturation, the teacher would know to look elsewhere for a cause.

An additional use of considering acculturation as a factor in academic progress is that it would be useful in grouping and placing the new ESL student in the appropriate classes. Many times, ESL students are assigned to a specific grade level because of their age. Yet, because of culture shock, cultural differences and other problems in acculturation, this grade placement is incorrect, causing behavioral, emotional and academic problems. Eventually, at some point, the student needs to repeat a grade. This retention is often upsetting to the child and family.

The information about a student that is on an acculturation scale would also help teachers and administrators place a student more accurately when he is initially enrolled in the following way. Any student registering at a Portland Public School who indicates a language other than English is spoken in the home is required to be tested and meet with Bilinglal community Agents at the Child Service center. At that time, the Community Agents determine the child's English language 
skills and are able to collect personal history information about the child from the adult who brought him, in their native language. If a child acculturation scale was also administered at that time, its results could also be passed on to the school and ESL teacher along with other data collected. This information would help the building staff In identifying correct grade placement.

For example, last year a $61 / 2$ year old ESL student arrived at Beach School. He was placed in a fist grade classroom - based solely on his age. After one week in first grade, it became clear that this student needed to be in a kindergarten room - he had no previous school experience, no English skills and was in a state of culture shock. He was withdrawing, crying and falling asleep in class. Fortunately, it was possible to change his classroom before problems worsened. Although his age identified him as a first grader, his needs were better met in a kindergarten classroom, where adapting to school is a major part of the curriculum for the young child. Considering acculturation, which takes into account many of the variables that effect the child and his ability to learn and participate in school would aid in finding the appropriate grade level for a new ESL student.

It follows that identifying a student's degree of acculturation would also aid in determining when a student is ready to exit from an ESL program and be able to maintain 
academic progress, family communications and school responsibilities on his own. Many factors need to be taken into account when exiting a student. To be more specific and because this study involves students in Portland Public Schools, one gulde that could be used to describe an acculturated child is the exit criteria used by some Portland Public Schools' ESL teachers. (Blackton, 1985) This criteria is used for exiting a student from ESL classes and support services and highly correlates with the behaviors that an acculturated chlld would exhibit. They are as follows:

1. Be communicatively competent in English. In other words, be able to express himself, carry out responsibilities and show an understanding of his environment.

2. Choose to interact within the classroom or outside with non-native as well as native children.

3. Accomodate to the learning style of the classroom and different role behaviors in the school.

4. Be able to separate home reality and school reality and meet the needs of each with appropriate behaviors.

5. Show academic progress and English gain, working toward meeting grade level requirements in the public school.

6. Exhibit a positive feeling of self-worth and 
ability to learn.

often, only his grades and test scores are considered. In one case a number of students were exited from ESL by an ESL teacher using IDEA level achievement only, and had to be re-enrolled in ESL classes three years later. For several years they had been without ESL support when, in fact, they needed 1t. This study shows that English competency is not the only variable that suggests a readiness to exit ESL. Knowing individual student degree of acculturation could be used to help ESL teachers decide when it is appropriate to exit students since it takes into account socio-cultural, ethnic identity and linguistic variables.

\section{CONCLUSION}

The results and research reviewed in this study inform and remind us of the fragility and strengths of children, their abilities to adapt to new circumstances, their special needs during acculturation and how we can better help them. Application of this knowledge in even a small way could help to bring progress and growth to our immigrant students and our growing country. 
Adler, Peter, "Multicultural Man," Intercultural Communication: A Reader, edit. Samovar and Porter, Wadsworth Pub. Co., 1976.

Alley, J.. "Better Understanding of the Indochinese Students," Education, Vol. 101, p.111-114, 1980.

Barna, La Ray, nintercultural Communication stumbling Blocks," Intercultural Communication: A Reader, edit. Samovar and Porter, Wadsworth Pub. Co., 1976.

Becker, Ernest, The Birth and Death of Meaning, The Free Press, New York, 1962 .

Bere, M., "A Comparitive study of the Mental Capacity of Children of Foreign Parentage," Teachers College, Columbia University, N.Y. No. 154, 1924.

Berger and Luckmann, The Social Construction of Reality, Anchor Books, 1967 .

Berry, John W., "Acculturation as Varieties of Adaptation," Acculturation: Theory, Models and Some New Findings, edit. Padilla, Westview, 1980 .

Blackton, Rhona. "Exit Criteria for ESL Students," Memo to Darlene Durgan, Portland Public Schools, March 7, 1986.

Brislin, Richard W., Cross Cultural Encounters, Pergamon Press inc., 1981 .

Castaneda, Alfredo, Mersisting Ideological Issues of Assimilation in America," Cultural Pluralism, ed. Edgar G. Epps, Chicago, 1974 .

Condon, John C. and Yousef, Faithi, An Introduction to Intercultural Communication, Bobbs-Merrill Co., Inc., 1979 .

Day, Richard, "Silence and the ESL Child," TESOL Quarterly, Vol. 15, \#1, pages 35-39, March 1981.

Dumont, Robert, "Cherokee School Society and the Intercultural Classroom," Human Organization, Vol. 28 , \#, 1970 . 
Dyal, James A. and Ruth Y., "Acculturation, Stress and Coping," International Journal of Intercultural Relations, Vol. 5, p. 301-328, 1981.

Ellis, Arthur, "The Assimilation and Acculturation of Indochinese Children into American Culture," California State Department of Soclal Services, August, 1980.

Epstein, Noel, et.al. "Language, Ethnicity and the Schools," Policy Alternatives for Bilingual = Bicuitural Education (Pollcy Paper: No.4), Institute Educational Leadersh1p, 1977.

Fantin1, Mar1o D. and Weinstein, Gerald, The Disadvantaged, Harper and Row, 1968.

Franco, Juan N., "An Acculturation Scale for MexicanAmerican Children," Journal of General Psychology, \#108, p.175-181, 1983 .

Gaarder, Bruce, "Education of American Indian Chlldren," Annual Conference of the Southwest Council of Foreign Language Teachers, November 10, 1967.

Garcia, R. L., Learning in Two Languages, Phi, Delta, Kappa Educational Foundation, 1976.

Gordon, H., Assimilation in American Life, Oxford University Press, 1964.

Gordon, S. B., Ethnic and Socioeconomic Influences on the Home Language Experiences of Children, Southwestern Cooperative Educational Lab, New Mexico, 1970.

Hall, Edward T., Beyond Culture, Anchor Books, New York, 1977.

Handlin, Oscar, Children of the Uprooted. New York, 1966.

Henken, A. and Nguyen, L. T., Between Two Cultures: The Vietnamese in America, Century 21 Publishing, 1981.

Hoffman, N. H. Moses, The Measurement of Bilingual Background, Teachers College, Columbia University, New York, No. 623, 1934.

Instructor, "At Schools," November/December, 1985, p. 18-21.

Jasser, Ghais, "Biculturalism in the Sequential Teaching of Second Generation Immigrants," Revue Belge de Psychologie de Pedagogie, May/June, 1983, Vol. 45, p. $11-14$. 
Kim, Bok-Lim, "The Future of Korean American Children and Youth: Marginality, Biculturality, and the Role of the American Public School," National Institute of Education, 1980 .

Kim, Young Yun, "A Communication Approach to the Acculturative Process: A Study of Korean Immigrants in Chicago," International Journal of Intercultural Relations, Vol. 2, Summer, 1978 .

Krashen, Stephen D., Principles and Practices in Second Language Acquisition, Pergamon Press, 1982.

Ladd, M. R., "The Relation of Social, Economic and Personality Characteristics to Reading Ability," Teachers College, Columbia University, N.Y., No. 582, 1933.

Locke, Alain and Vernhard, When Peoples Meet, Hinds, Haydn and Eldridge, Inc., 1946.

Malinowski, B., The Dynamics of Culture Change, Yale University Press, 1945.

Marden, Charles and Meyer, Gladys, Minorities in American Society, D. Van Nostrand Co., Litton Educational Publishing Co., 1973.

Martinez, R., Norman, R., Delany, Harold, "A Children's Hispanic Background Scale," Hispanic Journal of Behavioral Sciences, June, 1984, \#6,2, p.103-112.

Milne, Nidea Moreno, "Issues and Concerns Related to the Education of Exceptional Bilingual Students," When Peoples Meet, New York, 1946.

Murdock, Maddor and Berg, "A Study of the Relation between Intelligence and the Acquisition of English," Nature and Nurture, Part 1, p. 343-353, Bloomington, lllinois, 1928.

Olmedo, E. L., "Acculturation: A Psychometric Perspective," American Psychologist, \#34, 1974.

Olmedo, Esteban, Martinez, Joe and Martinez, Sergio. "Measure of Acculturation for Chicano Adolescents," Psychological Reports, \#42, p. 159-170, 1978 .

Olmedo, Esteban and Padilla, Amado, "Empirical and Construct Validation of a Measure of Acculturation for MexicanAmericans," Journal of Social Psychology, \#105, p. 179187,1978 . 
Osgood, Charles, May, William, Mason, Murray, Cross Cultural Universals of Affective Meaning, University of Illinois Press, 1975 .

Padilla, Amado, Acculturation: Theory, Models and Some New Findings, Westuiew, 1980 .

Reyes, V. H., "Self-Concept and the Bicultural Child," Bridging Two Cultures, edited M. Cotera and L. Hoffard, Ayer Co. Publishers, 1980.

Samovar, L. and Porter, R., Intercultural Communication Reader, Wadsworth Publishing Co., 1976.

Sampson, George Eaton, Melville J. Herskovits, Columbia University Press, 1973.

Sarelle, Muriel R. and Troike, Rudolph C., "A Handbook of Bilingual Education," Tesol Quarterly, 1971.

Schumann. J., "The Acculturation Model for Second Languages Acquisition," Second Languages Aquisition and Foreign Language Teaching, Center for Applied Linguistics, p. $27-50,1978$.

Sczapocnik, Kurtines and Fernandez, "Bicultural Involvement and Adjustment in Hispanic Youth," International Journal of Intercultural Relations, 1980 .

Sermol, Dorothy, "Toward a Phenomological Based Perspective of Acculturation with Application to scottish Immigrants," MA Thesis, PSU, 1983.

Soldier, Lee Little, "To Soar with Eagles," Childhood Education, p. 185-191, 1985.

Teske, Raymond Jr., and Nelson, Barden H., "Acculturation and Assimilation: A Clarification," American Ethnologist I, May, 1974 .

Thomas, Carl H. and James L., Bilingual Education Resource Guide, Oryx Press, 1982.

Thuy, Vuong G., "Bilingual Education: A Necessity or a Luxury," R. E. Research Associates, 1979.

Toufexis, Anastasia, "Caught Between Two Worlds," Iime. p. 84-85, July 8, 1985 .

Ui ibarri, Horacio and Holman, Richard, "Administration of Bilingual Administration," New Mexico University, 1975. 
Von Maltitz, Frances Willard, Living and Learning in Two Languages, McGraw-Hill, 1975. 
APPENDIX A

CHILDREN'S ACCULTURATION SCALE (CAS)

Nane

Ethnic Background (Check one)

White/Anglo

Hexican/Spanish Aerican, Chicano

Black

Native Anerican

Other

\section{Grade}

Gender: _ Male

Fenale

Circle the appropriate response for this child:

1. This student's English proficiency for a student at his/her grade level is:

$\begin{array}{ccccc}1 & 2 & 3 & 4 & 5 \\ \text { poor } & \text { below } & \text { average } & \text { above } & \text { excellent } \\ & \text { average } & & \text { average } & \end{array}$

2. Father's occupation:

$\begin{array}{ccccc}1 & 2 & 3 & 4 & 5 \\ \text { unemployed } & \text { laborer } & \text { blue collar } & \text { white collar } & \text { professional }\end{array}$

3. Hother's occupation:

$\begin{array}{ccccc}1 & 2 & 3 & 4 & 5 \\ \text { uneuployed } & \text { laborer } & \text { blue collar } & \text { white collar } & \text { professional }\end{array}$

4. To the best of your kinowledge which language is spoken at this child's hone:

$\begin{array}{ccccc}1 & 2 & 3 & 4 & 5 \\ \text { Spanish } & \text { Dostly } & \text { both } & \text { mostly } & \text { English } \\ \text { only } & \text { Spanish } & \text { Spanish } & \text { English } & \text { only } \\ & & \text { English } & & \end{array}$

5. In your opinion, which language does the child prefer to use:

$\begin{array}{ccccc}1 & 2 & 3 & 4 & 5 \\ \text { Spanish } & \text { astly } & \text { both } & \text { uostly } & \text { English } \\ \text { only } & \text { Spanish } & \text { Spanish } & \text { English } & \text { only } \\ & & \text { English } & & \end{array}$

6. In your opinion, would this child prefer to be identified as:

$\begin{array}{ccccc}1 & 2 & & 4 & 5 \\ \text { Hexican } & \text { Chicano } & \text { Mexican } & \text { Spanish Averican } & \text { Anglo } \\ & & \text { Anerican } & \text { Latin Anerican } & \text { Anerican } \\ & & \text { Hispanic Alerican } & \text { or Uhite }\end{array}$


7. In your opinion, does this chlld associate with:

$\begin{array}{ccccc}1 & 2 & 3 & 4 & 5 \\ \text { Hispanics } & \text { mostly with } & \text { Hispanics and } & \text { nostly } & \text { Anglos } \\ \text { only } & \text { Hispanics } & \text { Anglos equally } & \text { Anglos } & \text { only }\end{array}$

8. Educational level of head of household:

\begin{tabular}{|c|c|c|c|}
\hline $\begin{array}{c}1 \\
-3 \text { yrs. }\end{array}$ & $4-9^{2}$ yrs. & $\begin{array}{c}3 \\
\text { sose high } \\
\text { school }\end{array}$ & $\begin{array}{c}4 \\
\text { high school } \\
\text { graduate }\end{array}$ \\
\hline
\end{tabular}

9. In your opinion, vould this child's music preference be:

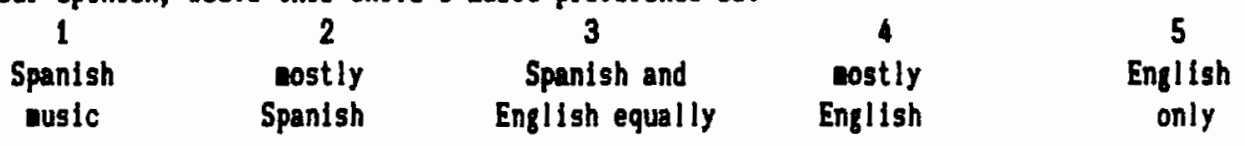

10. To the best of your knowledge, is this child:

$\begin{array}{ccccc}1 & 2 & 3 & 4 & 5 \\ \text { not an } & \text { a 1st } & \text { a 2nd } & \text { 3rd } & \text { a 4th or nore } \\ \text { Auerican } & \text { generation } & \text { generation } & \text { generation } & \text { generation } \\ \text { citizen } & \text { Merican } & \text { Merican } & \text { Merican } & \text { Anerican }\end{array}$


APPENDIX B - IDEA PROFILE

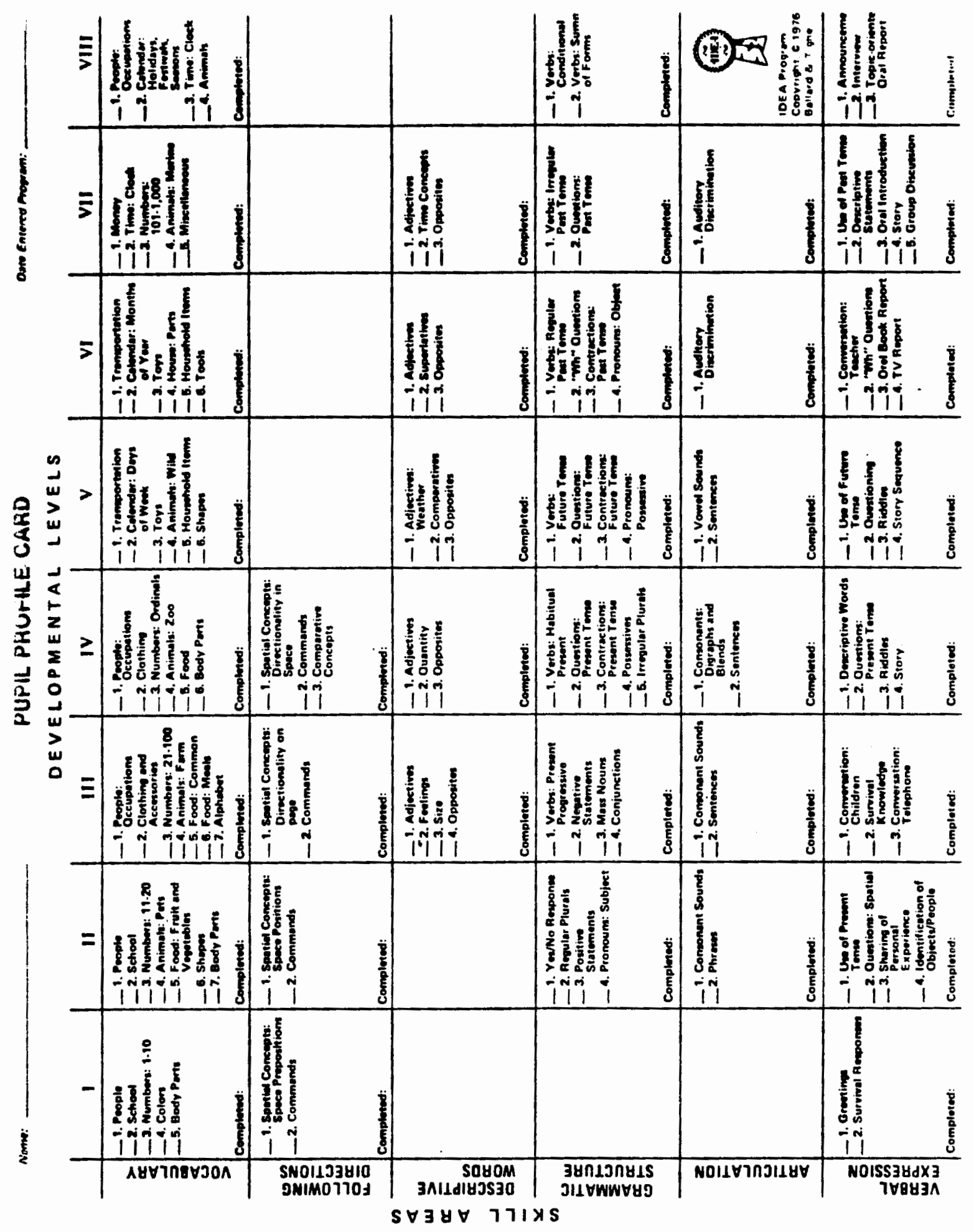

